Triboenvironment Dependent Chemical Modification of Sliding Interfaces in Ultrananocrystalline Diamond Nanowall Film: Correlation with Friction and Wear

Peer-reviewed author version

Rani, Revati; Panda, Kalpataru; Kumar, Niranjan; KAMATCHI JOTHIRAMALINGAM, Sankaran; Pandian, Ramanathaswamy; Ficek, Mateusz; Bogdanowicz, Robert; HAENEN, Ken \& I-Nan, Lin (2018) Triboenvironment Dependent Chemical Modification of Sliding Interfaces in Ultrananocrystalline Diamond Nanowall Film: Correlation with Friction and Wear. In: JOURNAL OF PHYSICAL CHEMISTRY C, 122(1), p. 945-956.

DOI: 10.1021/acs.jpcc.7b10992

Handle: http://hdl.handle.net/1942/26539 


\section{Article}

Subscriber access provided by READING UNIV

\section{Tribo-Environment Dependent Chemical Modification of Sliding Interfaces in Ultrananocrystalline Diamond Nanowall Film: A Correlation with Friction and Wear}

Revati Rani, Kalpataru Panda, Dr. Niranjan Kumar, Sankaran Kamatchi Jothiramalingam, Ramanathaswamy Pandian, Mateusz Ficek, Robert Bogdanowicz, Ken Haenen, and I-Nan Lin J. Phys. Chem. C, Just Accepted Manuscript • DOI: 10.1021/acs.jpcc.7b10992 • Publication Date (Web): 18 Dec 2017

Downloaded from http://pubs.acs.org on December 20, 2017

\section{Just Accepted}

"Just Accepted" manuscripts have been peer-reviewed and accepted for publication. They are posted online prior to technical editing, formatting for publication and author proofing. The American Chemical Society provides "Just Accepted" as a free service to the research community to expedite the dissemination of scientific material as soon as possible after acceptance. "Just Accepted" manuscripts appear in full in PDF format accompanied by an HTML abstract. "Just Accepted" manuscripts have been fully peer reviewed, but should not be considered the official version of record. They are accessible to all readers and citable by the Digital Object Identifier (DOI®). "Just Accepted" is an optional service offered to authors. Therefore, the "Just Accepted" Web site may not include all articles that will be published in the journal. After a manuscript is technically edited and formatted, it will be removed from the "Just Accepted" Web site and published as an ASAP article. Note that technical editing may introduce minor changes to the manuscript text and/or graphics which could affect content, and all legal disclaimers and ethical guidelines that apply to the journal pertain. ACS cannot be held responsible for errors or consequences arising from the use of information contained in these "Just Accepted" manuscripts. 


\title{
Tribo-Environment Dependent Chemical Modification of Sliding Interfaces in Ultrananocrystalline Diamond Nanowall Film: A Correlation with Friction and Wear
}

Revati Rani, ${ }^{\# a}$ Kalpataru Panda, ${ }^{\mathrm{b}}$ Niranjan Kumar, ${ }^{\# a}$ Kamatchi Jothiramalingam Sankaran, ${ }^{\mathrm{c}, \mathrm{d}}$ Ramanathaswamy Pandian, ${ }^{\mathrm{a}}$ Mateusz Ficek, ${ }^{\mathrm{e}}$ Robert Bogdanowicz, ${ }^{\mathrm{e}}$ Ken Haenen, ${ }^{\mathrm{c}, \mathrm{d}}$ I-Nan Lin, ${ }^{\mathrm{f}}$

${ }^{a}$ Materials Science Group, Indira Gandhi Centre for Atomic Research, ${ }^{*} H B N I$, Kalpakkam 603102, Tamil Nadu, India

${ }^{b}$ Center for Nanomaterials and Chemical Reactions, Institute for Basic Science, Daejeon $305-$ 701, Republic of Korea

${ }^{c}$ Institute for Materials Research (IMO), Hasselt University, 3590 Diepenbeek, Belgium

${ }^{d} I M O M E C$, IMEC vzw, 3590 Diepenbeek, Belgium

${ }^{e}$ Department of Metrology and Optoelectronics, Faculty of Electronics, Telecommunications and Informatics, Gdansk University of Technology, 11/12 G. Narutowicza St., 80-233 Gdansk, Poland

${ }^{f}$ Department of Physics, Tamkang University, Tamsui, 251 Taiwan, Republic of China.

\begin{abstract}
Tribological properties of ultrananocrystalline diamond nanowall (UNCD NW) films were investigated quantitatively in three different and controlled tribo-environmental conditions, proposing the passivation and graphitization mechanisms. However, these mechanisms are rather complicated and possibly can be understood in well-controlled tribological conditions. It was shown that the friction and wear of these films were high in high-


vacuum and room temperature (HV-RT) tribo-condition in which the passivation of carbon dangling bonds was restricted and frictional shear-induced transformation of $\mathrm{sp}^{3}$ carbon into amorphous carbon (a-C) and tetrahedral amorphous carbon $(\mathrm{t}-\mathrm{aC})$ was noticed. However, the friction coefficient was reduced to the ultralow value in ambient atmospheric and room temperature (AA-RT) tribo-condition. Here, both passivation of dangling bonds through atmospheric water vapor and graphitization of the contact interfaces were energetically favorable mechanisms. Furthermore, the conversion of diamond $\mathrm{sp}^{3}$ into hydrogenated-graphitized phase was dominating mechanism for observed super-low friction coefficient and ultra-high wear resistance of films in high-vacuum and high-temperature (HV-HT) tribo-condition. These mechanisms were comprehensively investigated by micro-Raman and X-ray photoelectron spectroscopy analyses of the sliding interfaces.

\section{INTRODUCTION}

The crystalline diamond films are useful for several applications due to their unique microstructure and chemical properties. Diamond is a wide band gap material ${ }^{1}$ with high thermal conductivity, ${ }^{2}$ extreme hardness, ${ }^{3}$ high elastic modulus ${ }^{3}$ and unique friction and wear performances. ${ }^{4-6}$ All these outstanding properties of crystalline diamond are associated to the $\mathrm{sp}^{3}$-hybridized chemical bonding of carbon atoms in cubic tetrahedral unit-cell parameter. ${ }^{7,8}$ Some of these properties of single crystal and micro/nanocrystalline diamond films were studied reasonably well. Moreover, recently, field emission ${ }^{9,10}$ and tribological properties ${ }^{11,12}$ of ultrananocrystalline diamond (UNCD) films were found to be superior as compared to the micro/nanocrystalline counterpart. Boron enhanced growth of UNCD films showed improvement in physicochemical and electrochemical properties. ${ }^{13,14}$ This improvement is associated with 
unique morphology and microstructure of ultranano diamond grains embedded with wider grain boundaries which occupy short-ranged crystalline graphite and amorphous carbon (a-C) phases. Notably, improved tribological properties of crystalline diamond, including UNCD and diamond-like carbon (DLC) films are generally explained by two existing mechanisms i.e. passivation and graphitization of the sliding interfaces. ${ }^{5,6,12,15-21}$ In the passivation mechanism, the film surface being chemically inert is not much deformed which provides mechanical stability. In contrast, the transformation of $\mathrm{sp}^{3}$ crystalline diamond into $\mathrm{sp}^{2}$ and a-C phases is responsible for damage and deformation of the sliding interfaces. ${ }^{6,12,18}$ Several aspects including the internal chemical structure of films and tribo-test environment are governing factors for determining passivation and/or graphitization mechanisms. However, these important aspects are not yet quantitatively understood in the controlled atmosphere and high-temperature tribocondition in order to relate with friction and wear properties of the films.

Tribological properties of UNCD films show the strong dependence on humidity, gaseous environment and vacuum tribo-condition. ${ }^{16,22}$ At high humidity, the film showed ultralow friction coefficient and high wear resistance and this was associated to the passivation of dangling bonds of the sliding interfaces. ${ }^{16,22}$ Moreover, Maria-Isabel et al. showed ultralow friction of nanocrystalline $(\mathrm{NCD})$ films in water vapor medium which is associated with the $\mathrm{OH}$ and $\mathrm{H}$ passivation of the sliding surfaces. ${ }^{23}$ Such improved properties of these films were obtained even in dry environments where negligible rehybridization was observed and the low friction behavior was supported by passivation mechanism. ${ }^{16,23}$ In another study, low friction was measured in low humidity (5\%) condition and was understood due to graphitization of the sliding interfaces. ${ }^{24}$ Konicek et al. described that even low humidity is sufficient to passivate the 
graphitized sliding interfaces. ${ }^{16}$ Passivation mechanism of diamond surface was well described by adsorption-dissociation of water molecules. ${ }^{25}$

Interestingly, the friction coefficient was lower in more graphitized grain boundaries of UNCD films which was explained by the low shear resistance induced sliding mechanism between the graphitic sheets. ${ }^{11,12,26}$ Even under mild tribological conditions, tribo-induced sp ${ }^{3}$ to $\mathrm{sp}^{2}$ hybridization was detected at the surface of wear track resulting in the formation of thin amorphous $\mathrm{sp}^{2}$-rich carbon layer embedded with ultranano diamond grains. ${ }^{15}$ Moreover, Bouchet et al described that the graphitization and passivation are together an effective mechanism for low friction and wear. ${ }^{15}$ Passivation is essential even for $\mathrm{sp}^{2}$-tribo-induced phase which is a byproduct of $\mathrm{sp}^{3}$-hybridized carbon, yielding low friction. The tribo-induced transformation from tetrahedral amorphous carbon ( $\mathrm{t}-\mathrm{aC})$ and $\mathrm{UNCD}$ films to $\mathrm{a}-\mathrm{C}$ and $\mathrm{sp}^{2}$ phase was experimentally observed by X-ray absorption near-edge fine structure technique and theoretically simulated by molecular dynamics (MD). ${ }^{27}$ Zhang et al. observed such transformation in microcrystalline coarse grain diamond films in nitrogen atmosphere by Raman spectroscopy, resulting in low friction coefficient of $0.15{ }^{28}$ Furthermore, tribo-induced phase transformation in single crystal diamond, yielding $\mathrm{sp}^{2}$-hybridised amorphous layer was studied by MD simulations. ${ }^{29}$ The $\mathrm{sp}^{2}$ carbon phase in diamond and DLC films is more active in high temperature tribo-condition. Therefore, the improvement in tribological properties of these films are challenging mainly due to transformation possibility of carbon phases at high temperature. At elevated temperatures and in ambient atmosphere condition, the DLC films undergo gradual transformation from a highly disordered or amorphous state to an increasingly ordered or graphitic state. ${ }^{30,31}$ This is associated to thermodynamically unstable phase of DLC films. Therefore, friction and wear behaviors of DLC films are unstable and change with change in their chemical and structural properties at 
higher temperatures. The hydrogenated DLC films may provide low friction up to $300^{\circ} \mathrm{C}$ for shorter sliding cycles, but during repeated sliding process, these films tend to wear faster. ${ }^{30}$ However, DLC films with hydrogen-free ta-C phase may last longer. Moreover, friction coefficient of these films tend to increase with increasing test temperature due to thermal desorption of water and other adsorbed species. Li et al. have shown that the friction coefficient and wear rate of thermally annealed polycrystalline diamond films were reduced due to formation of the carbonaceous transfer films. ${ }^{32}$ Shabani et al. have investigated the high friction value of multilayer micro/nanocrystalline diamond films at elevated temperature due to dry contact condition. ${ }^{33}$ However, ultralow friction coefficient in polycrystalline diamond films was measured at moderate temperature in oxygen atmosphere. ${ }^{34}$ This was ascribed to the chemically stable adsorbed oxygen moiety formation on the film surface that saturates carbon dangling bonds of diamond films. ${ }^{35,36}$ Moreover, shear-induced graphitization of the sliding interfaces may possibly explain the low friction in polycrystalline diamond films. ${ }^{35,37}$ In high vacuum conditions, graphitization and amorphization of diamond films are substantial which has an adverse effect on friction and wear response. This can be explained by the lack of external passivation when chemical adsorbate is absent to passivate the unsaturated bonds at sliding interfaces. ${ }^{38,39}$ However, hydrogenated UNCD films show low/ultralow friction value in high vacuum condition due to passivation mechanism. ${ }^{26,40}$ This was performed by hydrogen atoms/molecules intrinsically present in the films. Moreover, at moderate temperature, surface graphitization of diamond films was favorable in reducing the friction in air and vacuum conditions. ${ }^{41,42}$ Furthermore, ultra-low friction coefficient with high wear resistance was measured at $200^{\circ} \mathrm{C}$ in UNCD films and this was explained by the formation of chemically passivated sliding interfaces. However, at higher temperature, tribological performance of these 
films were significantly degraded and failure happened mainly due to oxidation and amorphization/polymerization of the sliding interfaces. ${ }^{43}$ Therefore, passivation of dangling bonds and conversion of $\mathrm{sp}^{3}$ into $\mathrm{sp}^{2}$ and a-C mainly depend on the temperature and environmental conditions. However, it is quite difficult to understand the suitable mechanism of friction and wear behavior in high-vacuum and high-temperature tribo-conditions without substantial characterization of tribofilm which was produced at sliding interfaces. Sustainable performance of materials in above mentioned tribo-conditions is useful for high temperature and space applications. However, tuning the tribo-sustainable properties of thin films via tailoring morphology, chemical composition and microstructure is a challenging task.

Here, we report the deposition of tribologically novel and sustainable UNCD nanowall (NW) thin films using microwave chemical vapor deposition system employing the unique plasma conditions. To elucidate the comprehensive tribological properties, the test of UNCD NW films were conducted in the controlled tribo-environmental conditions such as ambient atmosphere and room temperature (AA-RT), high-vacuum and room temperature (HV-RT) and high-vacuum high-temperature (HV-HT). In order to explain the distinct underlying tribomechanisms, these tribo-atmospheres were used to manipulate the chemical nature of contact interfaces. The change in the chemical structure of tribo-interfaces was characterized by Raman spectroscopy and X-ray photoelectron spectroscopy with micrometer spatial resolution. Chemical modification of carbonaceous tribofilm at contact interfaces in three different triboconditions was quantitatively explained by shear induced amorphization/graphitization and passivation mechanisms. Moreover, friction and wear behavior was explained based on the chemical structure of tribofilms at the sliding interfaces.

\section{EXPERIMENTAL SECTION}


2.1. Film Deposition. UNCD nanowalls films were deposited on (100) oriented silicon substrate using microwave plasma enhanced chemical vapor deposition (MWPECVD; SEKI Technotron AX5400S, Japan) system. The base pressure inside the chamber was $10^{-4}$ Torr. Prior to diamond growth, the silicon substrate was seeded by spin-coating in the diamond slurry. ${ }^{44}$ The nanowalls have been fabricated using the following process conditions: gas mixtures of $\mathrm{CH}_{4}, \mathrm{H}_{2}$ and $\mathrm{N}_{2}$ with a total flow rate of $328 \mathrm{sccm}$, microwave power of $1300 \mathrm{~W}$, the process pressure of 50 Torr, and microwave radiation frequency of $2.45 \mathrm{GHz}$. During the deposition process, the substrate holder was heated up to $700^{\circ} \mathrm{C}$ by an induction heater, which was controlled by a thermocouple. The deposition parameters of these films differ from earlier UNCD nanowire films deposited in $\mathrm{CH}_{4} / \mathrm{N}_{2}$ plasma condition without the addition of $\mathrm{H}_{2} \cdot{ }^{11,12}$

2.2. Characterization Techniques. Morphology of these films was characterized by field emission scanning electron microscopy (FESEM, Zeiss Supra 55). High-resolution microstructure and crystallographic investigation of UNCD nanowall films were examined by transmission electron microscopy (TEM; JOEL 2100). Bonding structure of films surface, wear tracks and ball scars were studied by micro-Raman spectrometer (Andor SR-500i-C-R, wavelength $532 \mathrm{~nm}$ ). Chemical bonding of films surface, wear tracks and ball scars were characterized by energy dispersive X-ray spectroscopy (EDS). Wide range survey and highresolution X-ray photoelectron spectroscopy (XPS) of films and mechanochemically modified contact interfaces were recorded by Sigma probe-Thermo VG Scientific equipped with hemispherical analyzer and micro-focused monochromator X-ray source with spatial resolution of $50 \mu \mathrm{m}$. The XPS analysis was carried out using Al Ka radiation $(\mathrm{E}=1486.6 \mathrm{eV})$ with an energy resolution of $0.47 \mathrm{eV}$ in ultra-high vacuum at $10^{-10} \mathrm{Torr}$. 
2.3. Tribology Tests Condition. Friction and wear behaviors of UNCD NW films were studied by ball-on-disc high-vacuum high-temperature tribometer (HV-HT Anton Paar, Switzerland) operating in a circular motion mode. For friction measurements; normal load, sliding speed and diameter of sliding contact were $0.5 \mathrm{~N}, 50 \mathrm{rpm}$ and $5 \mathrm{~mm}$, respectively. Alumina $\left(\mathrm{Al}_{2} \mathrm{O}_{3}\right)$ ball with $6 \mathrm{~mm}$ diameter was used as a sliding counterbody. The hardness of $\mathrm{Al}_{2} \mathrm{O}_{3}$ ball is $12 \mathrm{GPa}$ and average roughness of $45 \mathrm{~nm}$. The above values were standardized and provided by the supplier (HV-HT Anton Paar, Switzerland). The tribo-tests were conducted in three different atmospheres: (a) AA-RT with ambient atmosphere and room temperature (b) HV-RT with vacuum level $\sim 5 \times 10^{-6}$ mbar and room temperature (c) HV-HT with vacuum level $\sim 5 \times 10^{-6}$ mbar and film temperature $\sim 623 \mathrm{~K}$. Two dimensional (2D) wear profile was measured by Dektak $6 \mathrm{M}-$ stylus profiler for the wear analysis.

\section{RESULTS AND DISCUSSION}

3.1. Morphology and Microstructure. SEM micrographs shown in Figure 1a indicated that UNCD NW films shows predominantly nanowall-like feature with the size of 200 to $300 \mathrm{~nm}$ in length. These features are homogeneously distributed all over the film surface. Figure $1 \mathrm{~b}$ shows the bright field TEM (BF-TEM) micrograph of UNCD NWs, revealing the unique granular structure of these films. The UNCD NW films consist of needle-like clusters of hundreds of nanometers in length. The selected area diffraction (SAED) pattern showed (111), (220), and (311) rings of diamond plane and a central diffuse ring of $\mathrm{sp}^{2}$-bonded carbon (nanographite or aC phase) or trans-polyacetylene (TPA) located in the grain boundaries. The presence of diffraction rings implies that the needle-like clusters are predominantly diamond and the diamond grains are randomly oriented, whereas the central diffuse ring is presumably 
contributed from the $\mathrm{sp}^{2}$-bonded carbons associated with the needle-like clusters. This is illustrated in the high-resolution TEM micrograph in more detailed (Figure 1c).
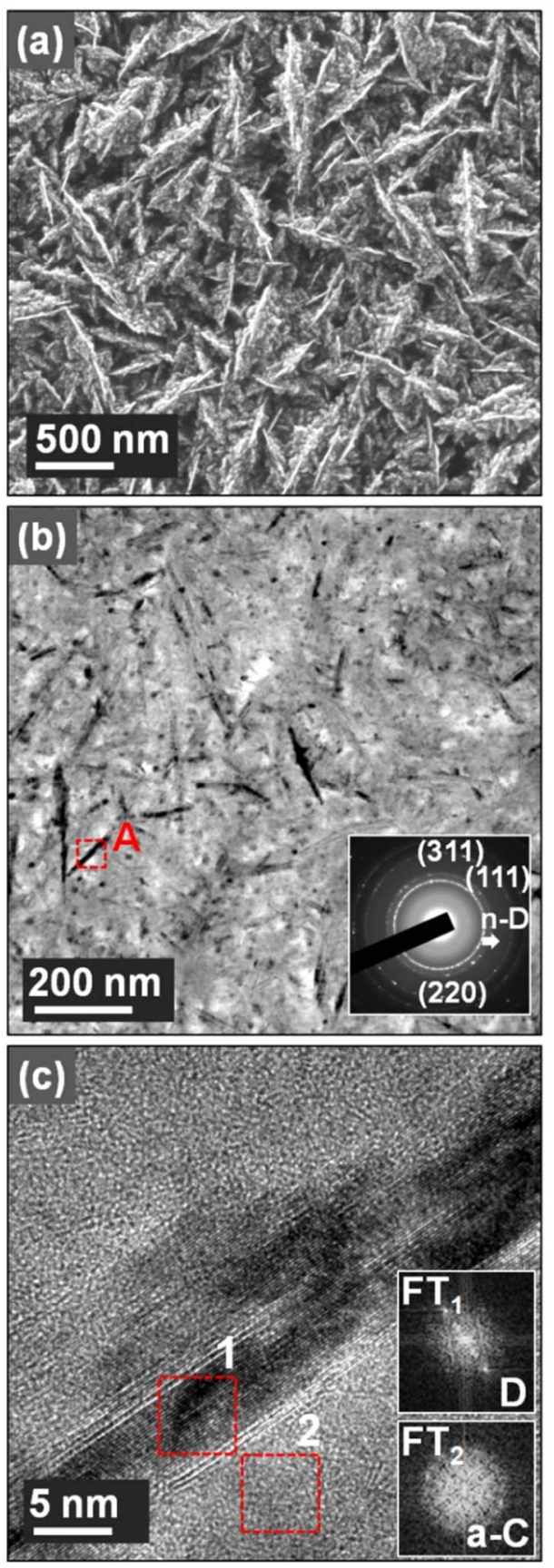

Figure 1. (a) SEM image of UNCD NW films surface, (b) typical TEM bright field (BF) micrograph with corresponding selective area electron diffraction (SAED) pattern shown as inset and (c) HRTEM image corresponding to the marked region " $A$ " of Figure 1(b) of UNCD 
NWs. The insets $F T_{1}$ and $F T_{2}$ of figure 1(c) show the Fourier-transformed (FT) diffractogram images corresponding to regions 1 and 2, respectively.

The needle-like clusters contain diamond about $5 \mathrm{~nm}$ in width and hundreds of nanometers in length as core and $\mathrm{sp}^{2}$-bonded carbon (nanographite or amorphous carbon) as shell. The $\mathrm{FT}_{1}$ and $\mathrm{FT}_{2}$ Fourier-transformed diffractogram further confirmed that the core and shell consists of diamond and $\mathrm{sp}^{2}$ - bonded carbon, respectively. There exists an extra ring with smaller size than (111) ring (indicated by the arrow in inset of Figure 1b), which corresponds to $n$-diamond (n-D), a metastable form of diamond with FCC structure and cell parameter of $0.356 \mathrm{~nm} \cdot{ }^{45,46}$ It is worth mentioning that the morphology and microstructure of the present films differ significantly from our published results and this fact is related to altered plasma condition during deposition process. ${ }^{11,12}$ Here, UNCD NW exists in nanowall feature embedded with a-C structure. However, in earlier work, nanowire like feature was formed. ${ }^{11,12}$

3.2. Bonding Structure of Bulk and Surface of Films. The bonding structure of bulk and surface of films were comprehensively investigated by Raman spectroscopy and XPS analyses and the results are shown in Figure 2. Raman spectra showed four deconvoluted peaks designated by $v_{1}\left(1168 \mathrm{~cm}^{-1}\right), v_{3}\left(1510 \mathrm{~cm}^{-1}\right), \mathrm{D}\left(1329 \mathrm{~cm}^{-1}\right)$ and $\mathrm{G}\left(1582 \mathrm{~cm}^{-1}\right)$ bands which are the nondiamond phases existing in the grain boundaries ${ }^{47}$ (Figure 2a). The $v_{1}$ and $v_{3}$ correspond to TPA phases ${ }^{48,49}$ and the other two $D$ and $G$ bands with $I(D) / I(G)$ ratio of 1.65 shows the signature of a-C and graphite phases. ${ }^{50}$ Fundamental phonon band of diamond in UNCD is not observable mainly for two reasons: (a) broadening effect due to phonon confinement in ultranano grains and (b) quenching of diamond band due to appearance of broad nondiamond D band at similar Raman shift. Such a Raman characteristic is a signature of UNCD films. ${ }^{11,51}$ More detailed surface bonding characteristics was investigated by XPS (Figure 2b-d). Survey spectra 
in Figure $2 \mathrm{~b}$ showed photoelectron emission of carbon $(\mathrm{C} 1 \mathrm{~s})$ and oxygen $(\mathrm{O} 1 \mathrm{~s})$ at 285.5 and $531.1 \mathrm{eV},{ }^{52}$ respectively, of UNCD NW film and $\mathrm{C} / \mathrm{O}$ ratio is 2.92. A small fraction of oxygen at films surface is associated to the contamination due to exposure in ambient environment. Moreover, Auger photoelectron shift of these elements as OKLL and CKLL are also observed. Another weak chemical shift of N1s photoelectron was observed at $399.32 \mathrm{eV}$ which signifies the impurities associated to nitrogen gas in plasma medium used for the deposition of UNCD NW films. X-ray photoelectron emission of Si2p and Si2s lines, related to the silicon substrate, were also observed in trace level as impurities.
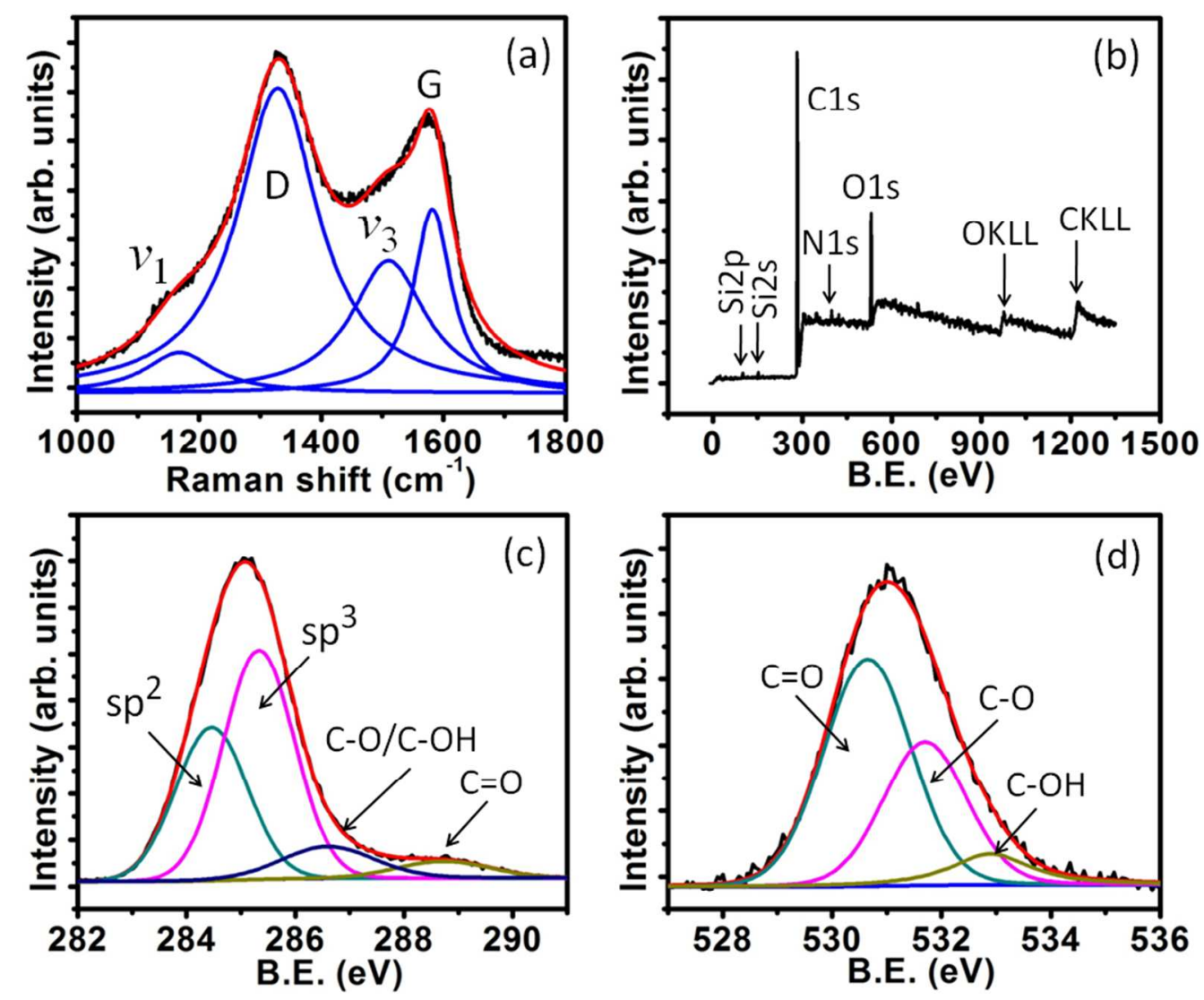

Figure 2. (a) Raman spectra and (b-d) XPS spectra of UNCD NW film surface: (b) survey spectra and high-resolution XPS: (c) Cls and (d) Ols X-ray photoelectron emission lines. 
High-resolution (HR) XPS of photoelectron emission bands of C1s and O1s are plotted in Figure $2 \mathrm{c}$ and $2 \mathrm{~d}$, respectively. A broad $\mathrm{C} 1 \mathrm{~s}$ photoelectron emission spectrum is deconvoluted into four peaks at the binding energies of 284.46, 285.3, 286.6 and $288.7 \mathrm{eV}$. The background was subtracted following the Shirley method. ${ }^{53}$ The first two peaks are designated as $\mathrm{sp}^{2}$ and $\mathrm{sp}^{3}$ hybridized carbon and third and fourth peaks correspond to oxygen functional groups such as the carboxylic $(\mathrm{C}-\mathrm{O} / \mathrm{C}-\mathrm{OH})$ and carbonyl $(\mathrm{C}=\mathrm{O})$ groups, respectively. ${ }^{2,54,55}$ The ratio of $\mathrm{sp}^{3} / \mathrm{sp}^{2}$ phase is 1.48 and energy width of photoelectron emission for $\mathrm{sp}^{2}$ and $\mathrm{sp}^{3}$ peaks are equivalent to 1.55 and $1.54 \mathrm{eV}$, respectively. These films showed the large fraction of $\mathrm{sp}^{2}$ carbon phase as compared to earlier reported work ${ }^{11,12}$ and therefore, chemical properties of these UNCD NW films are distinctly different and novel for tribological applications. Moreover, deconvolution of broad $\mathrm{O} 1 \mathrm{~s}$ peak results in three photoelectron emission lines centered at binding energies of $530.65,531.7$ and $532.9 \mathrm{eV}$ that correspond to the $\mathrm{C}=\mathrm{O}, \mathrm{C}-\mathrm{O}$ and $\mathrm{C}-\mathrm{OH}$ functional groups, respectively. ${ }^{22,56}$ These groups are attainable due to the surface contamination and adsorption of atmospheric moisture and water vapor molecules.

3.3. Friction and Wear Characteristics. Friction and wear behavior of UNCD NW films distinctly differ depending upon their tribo-test environments (Figure 3). Two separate measurements for each tribo-condition were carried out and in each condition, the measurement was found to be reproducible. The saturated value of friction coefficient in AA-RT was $\sim 0.023$ (curve $\mathrm{a}_{1}$ ) which significantly increased to $\sim 0.17$ in HV-RT tribo-condition (curve $\mathrm{a}_{2}$ ) and in addition, early film failure was also noticed. However, the friction value was decreased to $\sim 0.002$ in HV-HT tribo-condition (curve $\mathrm{a}_{3}$ ). Raw data of friction curves in all three different atmospheres are presented in Supplementary Information (Figure S1). Wear dimension is found 
to be directly proportional to the friction value and it is lowest in HV-HT as compared to other two conditions (Figure 3d).
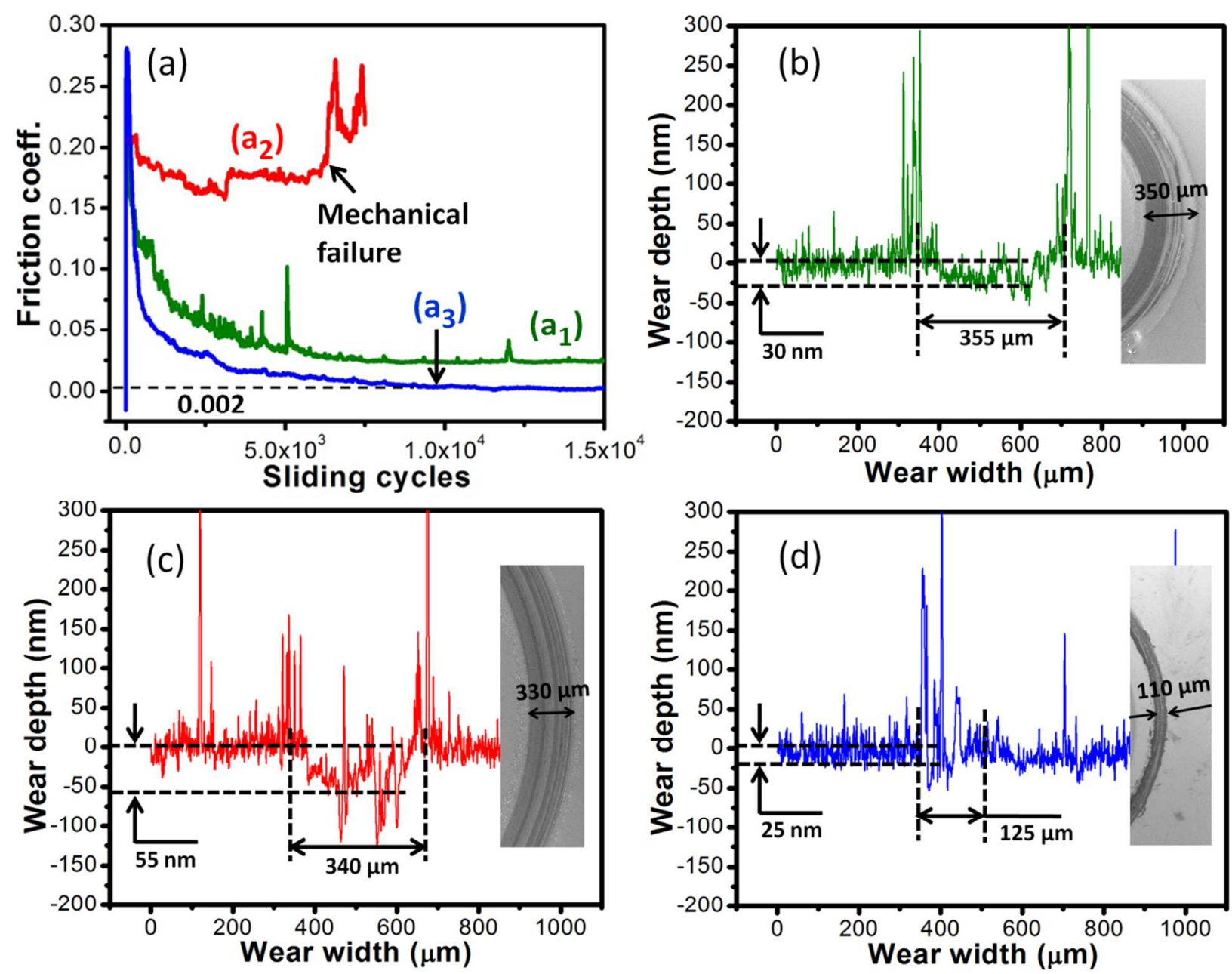

Figure 3. (a) Friction coefficient vs sliding cycles of UNCD NW film: $\left(a_{1}\right) A A-R T\left(a_{2}\right) H V-R T$ and $\left(a_{3}\right) H V-H T$ tribo-condition, and $2 D$ wear track profile in (b) $A A-R T$ (c) $H V-R T$ and (d) $H V$ HT tribo-condition. SEM images of the corresponding wear tracks are embedded for each condition; tribology parameters: load: $0.5 \mathrm{~N}$, speed: $50 \mathrm{rpm}$, ball: $\mathrm{Al}_{2} \mathrm{O}_{3}$ (dia. $6 \mathrm{~mm}$ ).

Four wear profile measurements were performed for each wear track at random locations and the data were quite repeatable. Wear dimension evidence is well supported by the low-resolution 
SEM images embedded in Figure 3b-d. Moreover, high-resolution SEM images of wear track formed in AA-RT condition showed that the nanostructure feature of UNCD NW films was sustained without much deformation (Figure S2). However, plastically deformed nanostructured morphology of UNCD NW in the wear track was observed in HV-RT tribo-condition (Figure S3). In this case, the wear dimension and extent of deformation of the ball is much higher compared to AA-RT condition. Contrasting SEM image of the wear track formed in HV-HT was observed with transformation of the UNCD NW morphology into layered deformed patches (Figure S4). Furthermore, in this case, deformation of ball and wear track dimensions much less. It is worth mentioning that in HV-HT condition, films were highly wear resistant with wear loss of $0.0016 \mathrm{~nm} /$ cycles. However, wear loss of films in AA-RT and HV-RT tribo-condition was $0.002 \mathrm{~nm} /$ cycles and $0.006 \mathrm{~nm} /$ cycles, respectively. It shows that the wear resistance of the films in HV-HT was improved up to $17 \%$ and $55 \%$ as compared to AA-RT and HV-RT tribocondition, respectively. Tribological properties of UNCD nanowire films were studied earlier by our group in ambient atmosphere and room temperature condition. ${ }^{11,12}$ However, in this present study, the value of friction coefficient of UNCD NW films is lower than UNCD nanowire films. Moreover, friction value of UNCD NW films is almost vanishing to the value of 0.002 with negligible wear loss in HV-HT condition. This value is much less compared to earlier reported work. ${ }^{11,12,16,22-24}$ To the best of our knowledge, this is a first tribological measurement on UNCD NW films conducted in three different controlled environments for comparative studies. Moreover, in-depth chemical characterizations of sliding interfaces were performed comprehensively to understand the governing friction and wear mechanisms. These are discussed in the following sections. 


\section{CHEMICAL COMPOSITION AND PHASE ANALYSIS OF SLIDING INTERFACES}

4.1. EDS Analysis of Sliding Interfaces. EDS analysis was carried out for qualitative elemental analysis of wear product and chemical composition of tribo-contact interfaces in three different tribological conditions. The results are presented in Figure S5-7. Wear track analysis showed the localized patch formation of $\mathrm{O}$ and $\mathrm{Al}$ entities as shown in the micrograph in AA-RT tribocondition (Figure S5a). A typical patch designated as $\left(\mathrm{a}_{2}\right)$ and corresponding spectra $\left(\mathrm{b}_{2}\right)$ is shown in Figure $\mathrm{S} 5 \mathrm{~b}$. These elements are wear product of $\mathrm{Al}_{2} \mathrm{O}_{3}$ ball which is formed due to deformation in AA-RT tribo-condition. However, whole area mapping denoted by $\left(\mathrm{a}_{1}\right)$ does not show the significant quantity of $\mathrm{O}$ and $\mathrm{Al}$ in spectra $\left(\mathrm{b}_{1}\right)$, indirectly indicating the localized formation of $\mathrm{Al}_{2} \mathrm{O}_{3}$ as a wear product. Here, the contribution of atmospheric oxygen along with oxygen from $\mathrm{Al}_{2} \mathrm{O}_{3}$ is worth to mention. In the similar tribo-condition, ball contact showed the signature of $\mathrm{C}$ and this is a product of transferlayer from UNCD film onto $\mathrm{Al}_{2} \mathrm{O}_{3}$ ball sliding contact. These are indicated in EDS mapping spots of $\left(c_{1}-c_{3}\right)$ in Figure S5c and corresponding spectra in $\left(\mathrm{d}_{1}-\mathrm{d}_{3}\right)$ in Figure $\mathrm{S} 5 \mathrm{~d}$. Atomic fraction of deformed wear product of $\mathrm{Al}_{2} \mathrm{O}_{3}$ ball was negligible in the wear track of HV-RT tribo-condition (Figure S6a). Therefore, the EDS spectra of the whole region (a) showed the negligible atomic fraction of $\mathrm{Al}$ and $\mathrm{O}$ and in this particular environment, the oxidation was also restricted due to the high vacuum condition (Figure S6b). However, bulk quantities of these elements present at the ball scar is an indication of $\mathrm{Al}_{2} \mathrm{O}_{3}$ ball (Figure S6d). More importantly, the X-ray signal of C is strong at the ball scar and this indicates the formation of transferfilm. The location at ball scar for EDS analysis is indicated in Figure S6c. The negligible fraction of $\mathrm{Al}$ and $\mathrm{O}$ was observed at the wear track of UNCD films in HVHT tribology condition. The EDS mapping spots are shown as $\left(\mathrm{a}_{1}-\mathrm{a}_{2}\right)$ in Figure S7a and corresponding spectra are presented in $\left(b_{1}-b_{2}\right)$ of Figure S7b, respectively. More importantly, in 
this case, the atomic fraction of $\mathrm{C}$ is high at the ball scar due to transferfilm formation. This is shown in spots $\left(c_{1}-c_{2}\right)$ in Figure S7c, and corresponding spectra in $\left(d_{1}-d_{2}\right)$ in Figure S7d. Qualitatively, it is concluded that carbon transferfilm is present on ball scar in all the three triboconditions. Atomic percentage of carbon is large in HV-RT and HV-HT tribology conditions compared to AA-RT. However, EDS technique being bulk sensitive is not sufficient to investigate the chemical phase composition of carbon at sliding interfaces. Therefore, the combination of spatially resolved Raman and XPS techniques were used for in-depth chemical phase composition analysis of sliding interfaces in three different tribo-conditions. These are discussed in the following sections.

4.2. Raman Spectroscopy of Sliding Interfaces. Wide frequency range of raw Raman spectra and the corresponding deconvoluted spectra of UNCD NW films in the specific range for AART tribo-condition are shown in Figure 4a and 4b, respectively. For comparison purpose, all the parameters of Raman spectrometer were kept similar. The Raman spectrum of the film surface is also presented for reference purpose. 


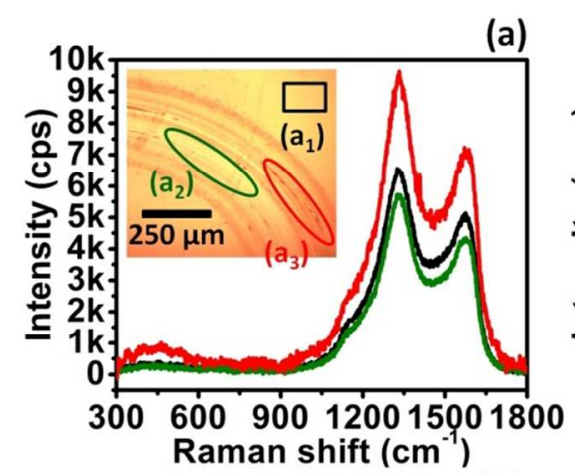

(b)
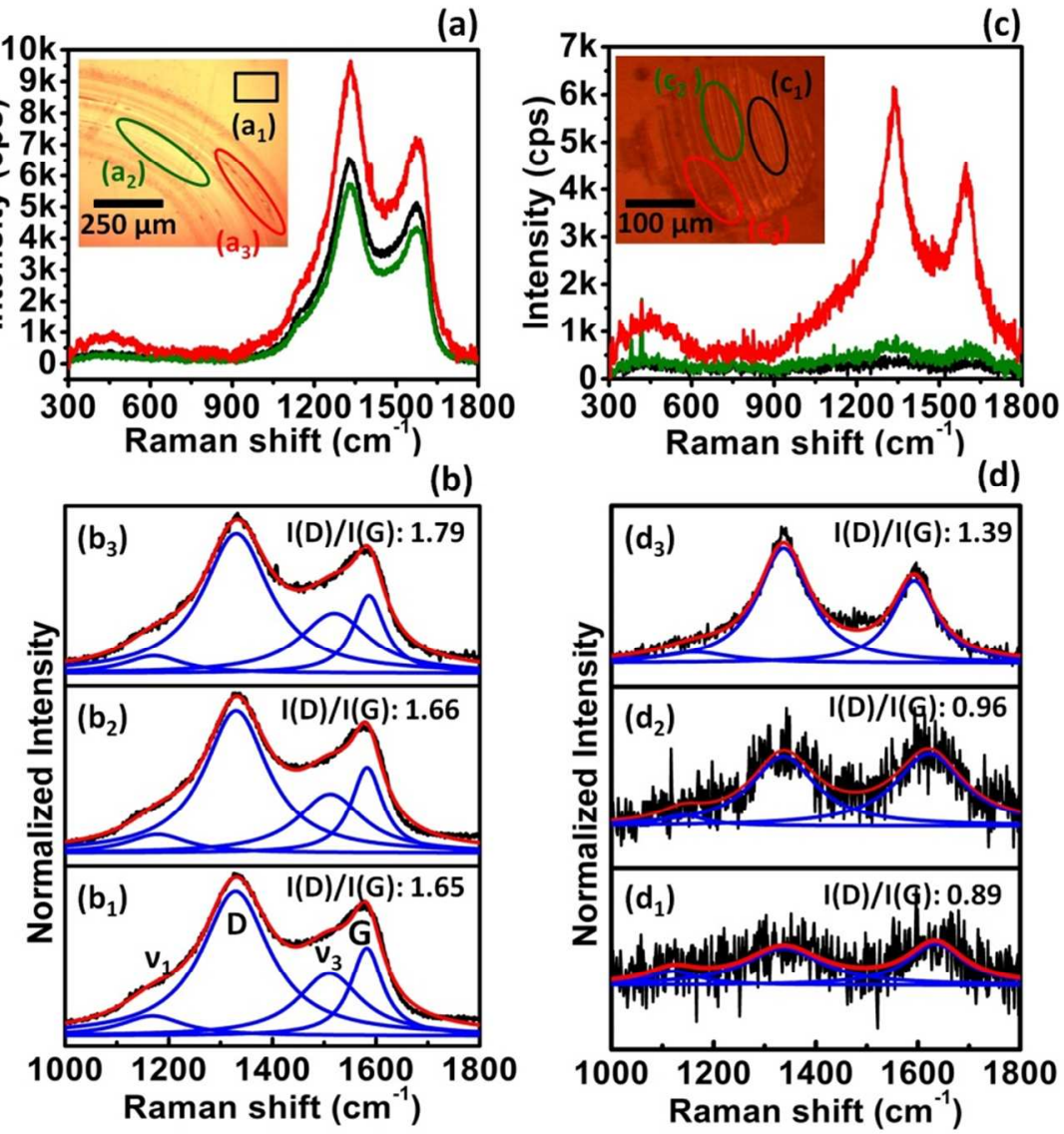

(d)

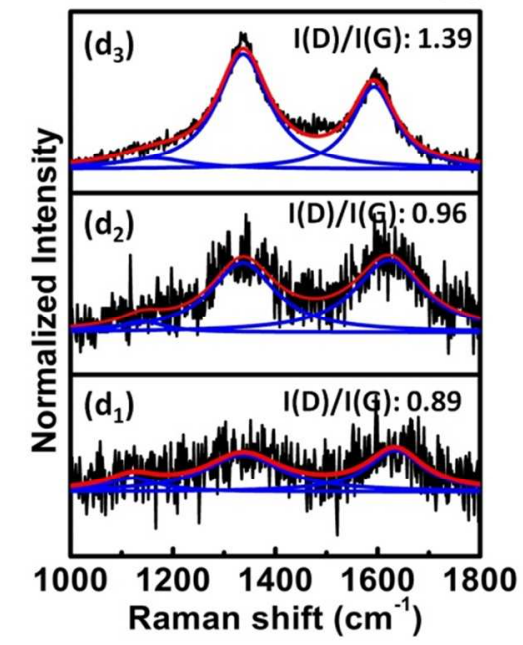

Figure 4. ( $a$ and b): Raw data of Raman spectra of film surface $\left(a_{1}\right)$ and inside the wear track $\left(a_{2}\right) \&\left(a_{3}\right)$ and corresponding deconvoluted spectra $\left(b_{1}-b_{3}\right)$, respectively; (c and $\left.d\right)$ : raw data of Raman spectra at ball scars $\left(c_{1}-c_{3}\right)$ and deconvoluted spectra $\left(d_{1}-d_{3}\right)$, respectively; tribology parameters: load: $0.5 \mathrm{~N}$, speed: $50 \mathrm{rpm}$, ball: $\mathrm{Al}_{2} \mathrm{O}_{3}$ (dia. $6 \mathrm{~mm}$ ), condition: ambient and room temperature (AA-RT).

Chemical structure of the UNCD NW wear track is stable and does not show the large difference in $\mathrm{I}(\mathrm{D}) / \mathrm{I}(\mathrm{G})$ value (Figure $4 \mathrm{~b}$ ). This ratio is an important parameter for the determination of the chemical structure of carbon phase.$^{50}$ However, the marginal increase in this ratio locally inside the wear track signifies slight enhancement in $\mathrm{a}-\mathrm{C} / \mathrm{sp}^{2}$ phase. This change clearly showed the increase in intensity counts in $\left(a_{3}\right)$ of Figure $4 a$. Moreover, D and G peak position inside the wear track is quite similar to the film surface. There is not much change in TPA phase inside the wear track and this fact directly points towards the stable UNCD structure in AA-RT tribo-condition. 
Chemical stability of this structure can be explained by passivation of sliding interfaces through ambient atmospheric chemical species. Similar Raman shift at the ball scar clearly indicates the formation of carbonaceous film (Figure 4c). However, peak shape, intensity and peak position of tribofilm locally differs at the ball scar which is an indication of heterogeneous carbonaceous transferfilm formation. This is shown in deconvoluted spectra $\left(d_{1}-d_{3}\right)$ of Figure $4 d$. Moreover, $\mathrm{I}(\mathrm{D}) / \mathrm{I}(\mathrm{G})$ value is less and the blue shift in $\mathrm{D}$ and $\mathrm{G}$ bands is noticed at the ball scar compared to wear track. This is a direct indication of shear induced a-C to graphitization in the ambient atmospheric condition. ${ }^{57}$ This may also be confirmed by the weakness of TPA phase due to the chemical modification of UNCD structure. Further, the altered shape of the Raman bands with the decrease in $\mathrm{I}(\mathrm{D}) / \mathrm{I}(\mathrm{G})$ value in the range of 0.9 to 1 was observed at most of the places of ball scar. However, locally this value was reached to 1.4 which showed stable tribofilm formation of chemically modified UNCD NW phase at the ball scar.

UNCD structure of wear track in the HV-RT tribo-condition is also stable and the Raman bands are more or less comparable to virgin UNCD film surface. The results of Raman spectra of wear track in HV-RT tribo-condition are shown in Figure 5a-b. 


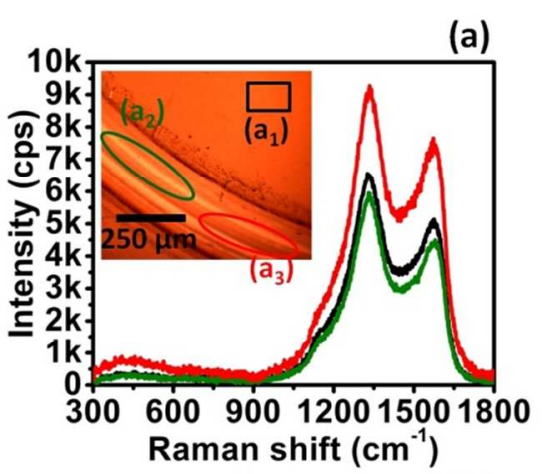

(b)

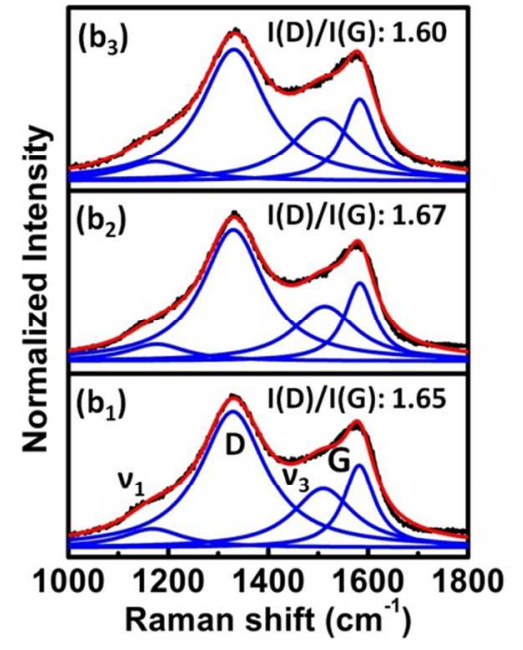

(c)

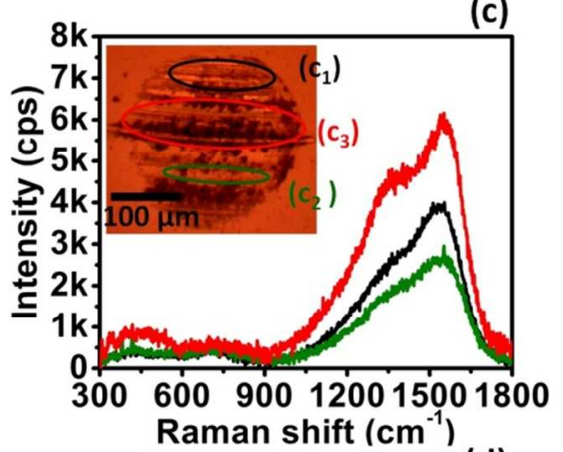

(d)

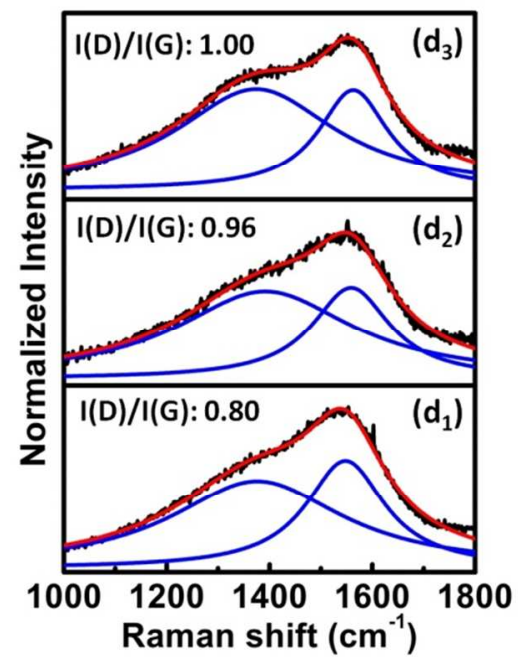

Figure 5. ( $a$ and b): Raw data of Raman spectra of film surface $\left(a_{1}\right)$ and inside the wear track $\left(a_{2}\right) \&\left(a_{3}\right)$ and corresponding deconvoluted spectra $\left(b_{1}-b_{3}\right)$, respectively; ( $c$ and $\left.d\right)$ : raw data of Raman spectra at ball scars $\left(c_{1}-c_{3}\right)$ and deconvoluted spectra $\left(d_{1}-d_{3}\right)$, respectively; tribology parameters: load: $0.5 \mathrm{~N}$, speed: $50 \mathrm{rpm}$, ball: $\mathrm{Al}_{2} \mathrm{O}_{3}$ (dia. $\left.6 \mathrm{~mm}\right)$, condition: high-vacuum $\left(5 \times 10^{-}\right.$ ${ }^{6}$ mbar) and room temperature (HV-RT).

In this $H V-R T$ condition, Raman peak parameters such as peak shape, peak position, I(D)/I(G) value and TPA phase of UNCD in wear track are quite similar to the wear track formed in AART tribo-condition. However, the chemical structure of carbonaceous tribofilm formed at the ball scar is completely transformed into a-C and $\mathrm{t}-\mathrm{aC}$ structure. ${ }^{58}$ This is noticed by the significant change of peak shape, peak position and modified value of $I(D) / I(G)$ ratio as shown in $\left(d_{1}-d_{3}\right)$ of Figure $5 \mathrm{~d}$. In this condition, the blue shift in $\mathrm{D}$ and red shift in $\mathrm{G}$ bands was observed as 
compared to carbon structure of wear track. Here, TPA phase is completely disappeared and this could be a strong indication for the conversion of UNCD into a-C and t-aC structure. This could be possible due to the high frictional energy which acts as activation energy for such transformation. Therefore, in case of HV-RT, the ball scar is fully covered by bulk tribofilm of a$\mathrm{C}$ and $\mathrm{t}-\mathrm{aC}$ phases. Thus, in this particular condition, sliding occurred between UNCD NW film and $\mathrm{a}-\mathrm{C} / \mathrm{t}-\mathrm{aC}$ structure on ball side.

Distinct changes in Raman spectra of the sliding interfaces in HV-HT tribology condition were noticed as shown in Figure 6a-d. Here, $\mathrm{I}(\mathrm{D} / \mathrm{I}(\mathrm{G})$ value of film surface is 1.52 as shown in $\left(a_{1}\right)$ of Figure 6a. This value is less compared to the ambient UNCD film as shown earlier in Figure $2 \mathrm{a}$ and $\left(\mathrm{a}_{1}\right)$ of Figure $4 \mathrm{a}$.

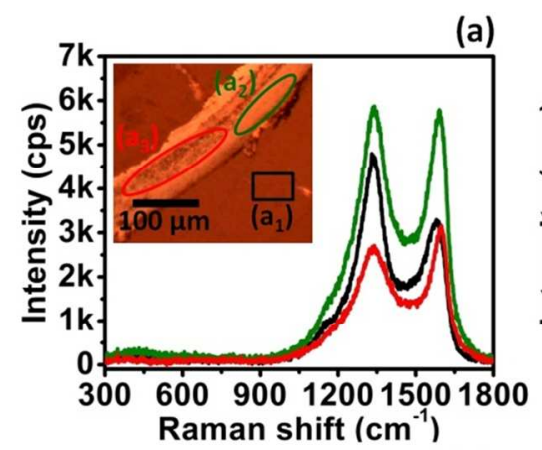

(b)

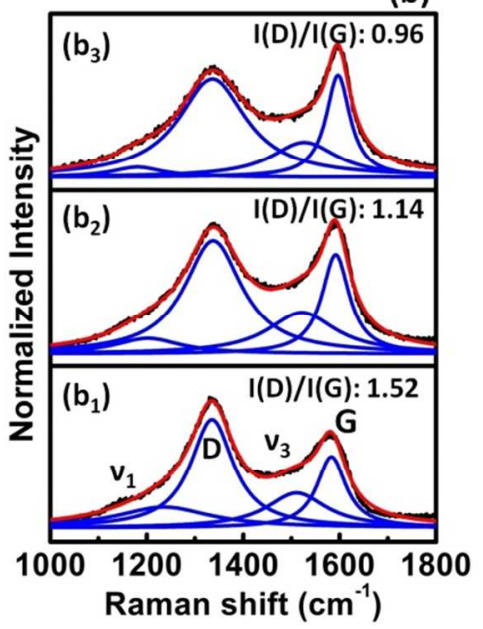

(c)

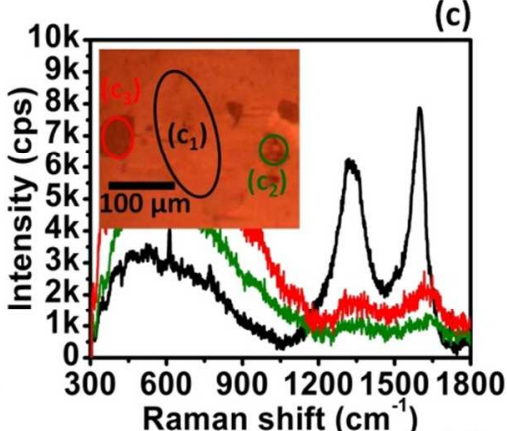

(d)

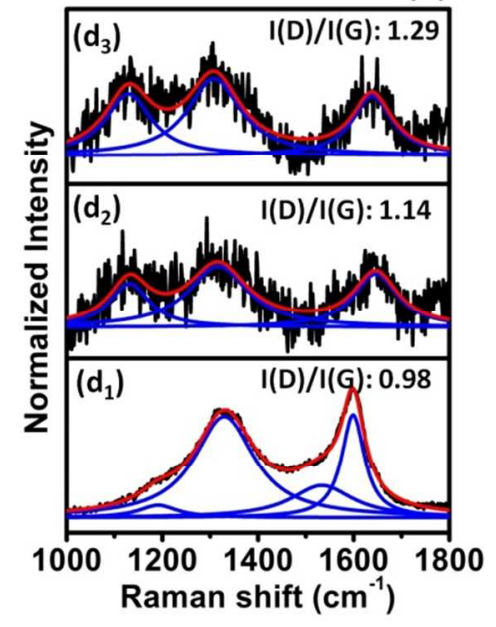

Figure 6. ( $a$ and $b$ ): Raw data of Raman spectra of film surface $\left(a_{1}\right)$ and inside the wear track $\left(a_{2}\right) \&\left(a_{3}\right)$ and corresponding deconvoluted spectra $\left(b_{1}-b_{3}\right)$, respectively; ( $c$ and $\left.d\right)$ : raw data of 
Raman spectra at ball scars $\left(c_{1}-c_{3}\right)$ and deconvoluted spectra $\left(d_{1}-d_{3}\right)$, respectively; tribology parameters: load: $0.5 \mathrm{~N}$, speed: $50 \mathrm{rpm}$, ball: $\mathrm{Al}_{2} \mathrm{O}_{3}$ (dia. $\left.6 \mathrm{~mm}\right)$, condition: high-vacuum $\left(5 \times 10^{-}\right.$ ${ }^{6}$ mbar) and high-temperature (623 K) (HV-HT).

Moreover, at high vacuum high-temperature condition, the D and G bands are blue shifted indicating temperature induced annealing which tends to reorient the carbon structure into more ordered $\mathrm{sp}^{2}$ phase. However, $\mathrm{I}(\mathrm{D}) / \mathrm{I}(\mathrm{G})$ ratio is significantly decreased in the wear track as compared to the film surface as shown in $\left(\mathrm{b}_{2}-\mathrm{b}_{3}\right)$, Figure $6 \mathrm{~b}$. For better quantitative analysis, Raman spectra are obtained at several locations of wear track in all three different tribology conditions (Figure S8). The Raman analysis showed the shift of D and G bands to higher wavenumber and decrease in $\mathrm{I}(\mathrm{D}) / \mathrm{I}(\mathrm{G})$ ratio in HV-HT condition. This behavior describes bulk graphitization of the contact surface ${ }^{57}$ and it is contrasting to the wear track formed in AA-RT and HV-RT tribo-condition as mentioned above. This indicates that the contact pressure at high temperature in high vacuum tribo-condition is a deterministic factor to reorient the disordered $\mathrm{sp}^{2}$ into more ordered $\mathrm{sp}^{2}$ phase. Moreover, conversion of $\mathrm{sp}^{3}$ to $\mathrm{sp}^{2}$ phase is also possible and it depends on the activation energy which is gained by the temperature and contact pressure. Most portion of the ball scar is covered by graphitized transfer film where $\mathrm{I}(\mathrm{D}) / \mathrm{I}(\mathrm{G})$ ratio is 0.98 as shown in $\left(d_{1}\right)$ of Figure $6 \mathrm{~d}$. However, graphitized tribofilm is highly distorted at few localized positions of the ball scar $\left(d_{2}-d_{3}\right)$ in Figure $6 d$. This is confirmed by the distinct shape of Raman bands with the increase in $I(D) / I(G)$ value. Here, raw data of $\left(c_{2}-c_{3}\right)$ in Figure $6 c$ showed very weak intensity of $\mathrm{D}$ and $\mathrm{G}$ bands which indicates the thin layer of distorted carbon structure. It is worth mentioning that Raman spectroscopy is a bulk sensitive technique and therefore, formation of such above mentioned phases is a bulk phenomenon. This was earlier reported by Bouchet $e t$ al. which showed formation of $40 \mathrm{~nm}$ thick $\mathrm{sp}^{2}$ rich carbon layer at the top of coating. ${ }^{15} \mathrm{The}^{2}$ 
hybridization change of sliding DLC surfaces under ultralow friction regime was also observed for amorphous ta-C films with even larger thickness of $50 \mathrm{~nm} .{ }^{59}$

3. X-ray Photoelectron Spectroscopy of Ball Scar. XPS was used for more insightful surface chemical analysis of tribofilm deposited on the ball contact region during the sliding process. This is an essential tool for understanding the friction behavior in three different tribo-conditions. The spatial resolution of XPS was $50 \mu \mathrm{m}$ and therefore, it was possible to focus the X-ray at specific locations inside the wear scar region of the ball surface. For this purpose, mainly deformed and less deformed regions were selected at each ball scar for quantitative chemical analysis. It is worth mentioning that these selected regions are representative of full scar. The common spots for Raman and XPS were located for comparative chemical analysis. Survey XPS showed well resolved C1s and O1s photoelectron shift obtained from the ball scar region in three different tribo-conditions such as AA-RT, HV-RT and HV-HT. These spectra are shown in Figure 7-9b and the corresponding physical locations of spectra are indicated in optical images in Figure 7-9a, respectively. These results show the carbonaceous tribofilm formation at the $\mathrm{Al}_{2} \mathrm{O}_{3}$ ball with adsorbed oxygen content. Survey spectra showed that in AA-RT tribo-condition, C/O ratio is less at the deformed region (0.51) as compared to the plain/less deformed region $(0.68)$ and intensity of the alumina peaks (Al2p and Al2s) is strong in deformed region (Figure $7 b$ ). These regions are located as $\left(a_{1}\right)$ and $\left(a_{2}\right)$ in Figure $7 a$. 

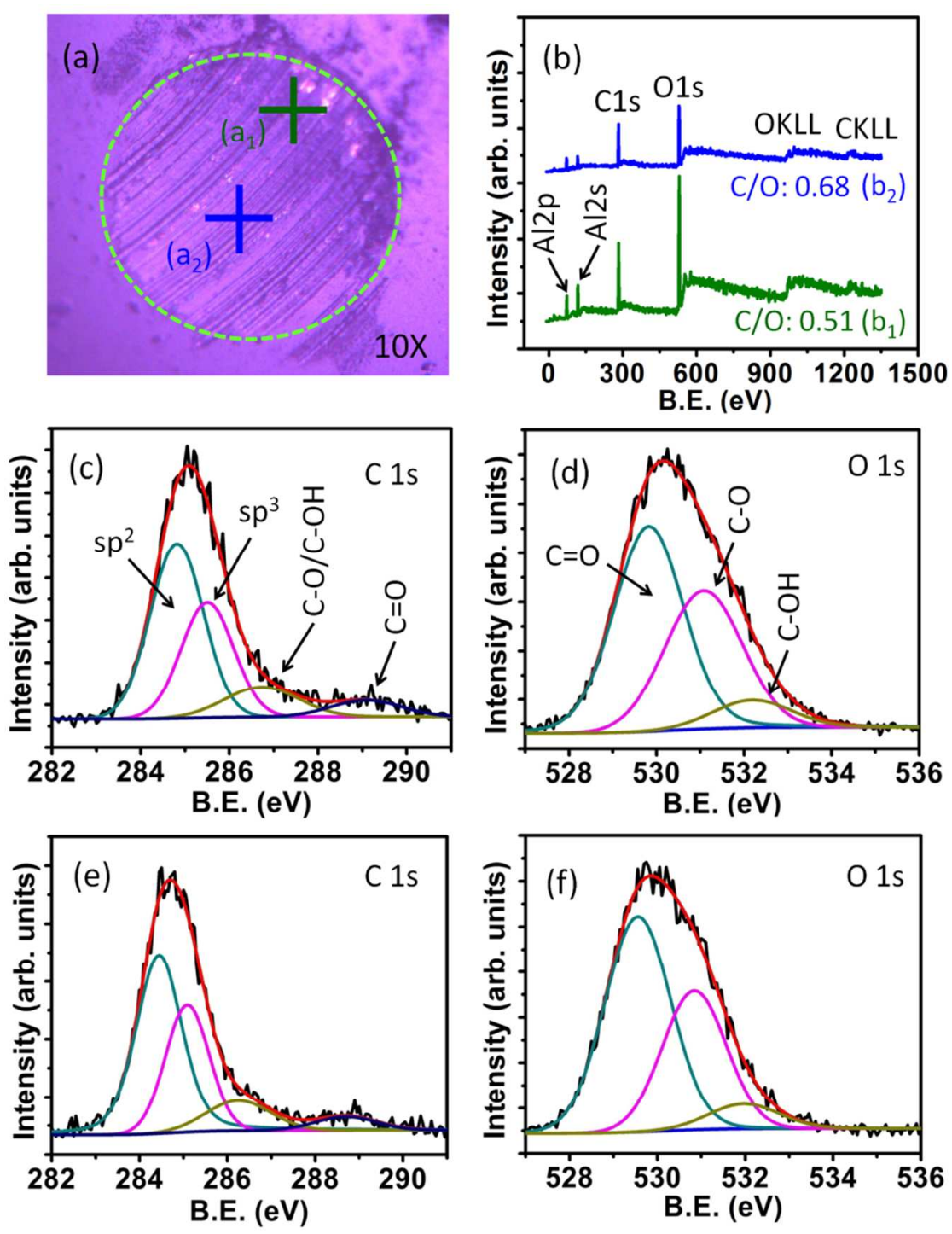

Figure 7. (a) Optical image of ball scar in AA-RT tribo-condition: $\left(a_{1}\right)$ deformed and $\left(a_{2}\right)$ less deformed region and corresponding survey XPS spectra of $\left(b_{1}\right)$ and $\left(b_{2}\right)$, respectively; HR-XPS of $C 1 s$ and $O 1 s$ of ( $c$ and $d)$ deformed and (e and f) less deformed region, respectively.

This indicates the excess exposure of alumina at the deformed region. Here, $\mathrm{C} / \mathrm{O}$ ratio is much lower as compared to the virgin film surface due to tribo-induced adsorption of oxygen (Figure 2b). The effective adsorption of oxygen is associated to the high energy of deformed $\mathrm{Al}_{2} \mathrm{O}_{3}$ ball surface which further react with the water vapor, forming adsorbed oxygen contamination. HRXPS of C1s photoelectron shift obtained from both the locations i.e. deformed and less deformed 
regions showed well-resolved deconvoluted $\mathrm{sp}^{3}$ and $\mathrm{sp}^{2}$ peaks with the contribution of oxygen functional groups. These are represented in Figure $7 \mathrm{c}$ and $7 \mathrm{e}$, respectively. The $\mathrm{sp}^{3} / \mathrm{sp}^{2}$ ratio in deformed and less deformed region is 0.65 and 0.6 , respectively. These values are much lower as compared to virgin film surface (Figure 2c) and it is an indicative of tribo-chemical conversion of $\mathrm{sp}^{3}$ to $\mathrm{sp}^{2}$ phase. In these regions, HR-XPS of O1s photoelectron shift showed well-resolved oxygen functional groups ${ }^{52}$ (Figure $7 \mathrm{~d}$ and $7 \mathrm{f}$ ) and spectral characteristics are similar to virgin film surface (Figure 2d). This indicates that the chemical environment of functional groups does not depend much on deformation of $\mathrm{Al}_{2} \mathrm{O}_{3}$ ball surface. In contrast, adsorption of oxygen quantity directly depends on the deformation which is related to the change in surface energy.

Survey spectra showed $\mathrm{C} / \mathrm{O}$ ratio of 0.68 and 0.48 at two different locations of the scar formed in HV-RT tribo-condition (Figure $8 b$ ). These regions are located in $\left(a_{1}\right)$ and $\left(a_{2}\right)$ of Figure $8 \mathrm{a}$, respectively. 

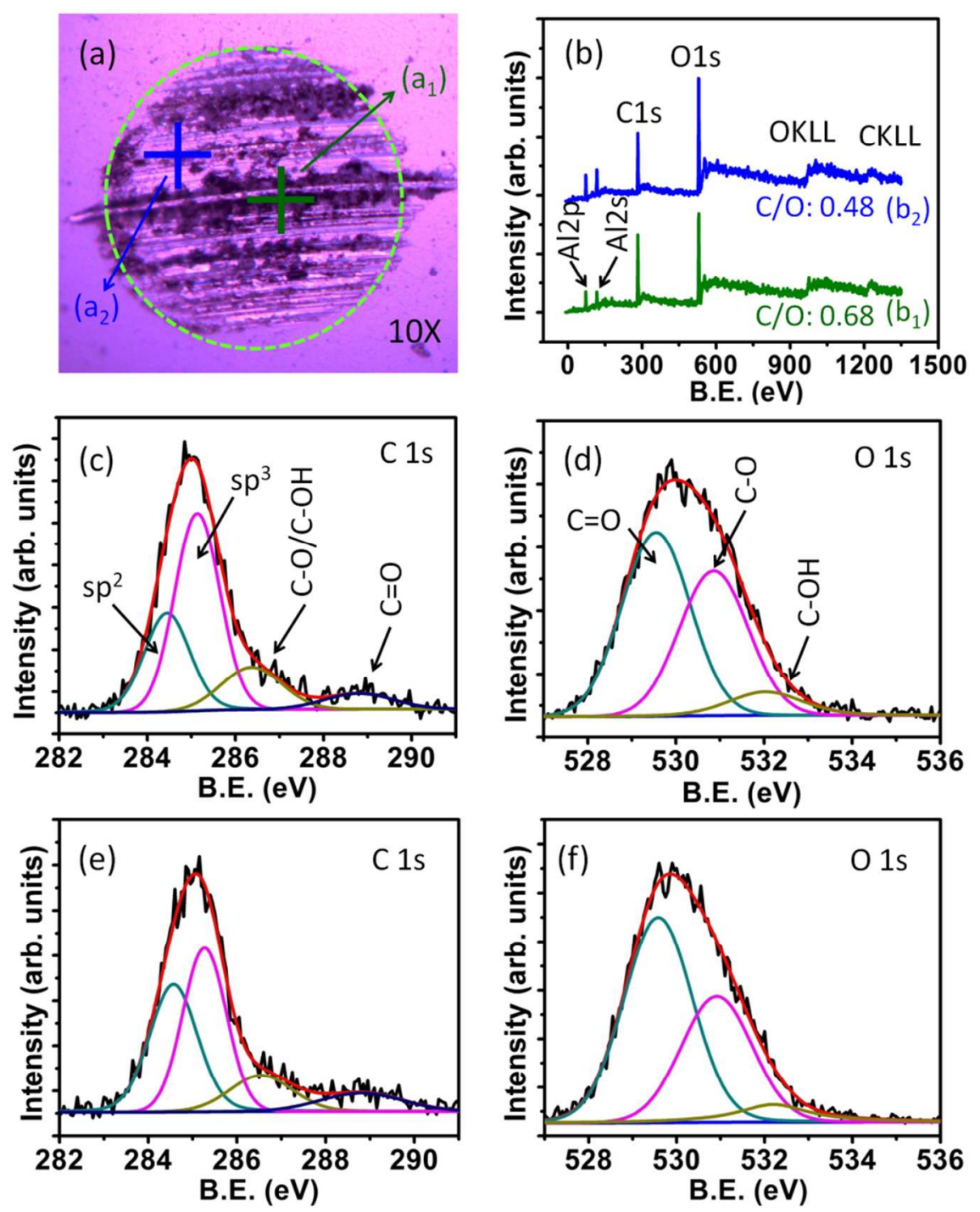

Figure 8. (a) Optical image of ball scar in HV-RT tribo-condition: $\left(a_{1}\right)$ deformed and $\left(a_{2}\right)$ less deformed region and corresponding survey XPS spectra of $\left(b_{1}\right)$ and $\left(b_{2}\right)$, respectively; HR-XPS of $C 1 s$ and $O 1 s$ of ( $c$ and d) deformed and (e and f) less deformed region, respectively.

In this condition, contribution of oxygen contamination is mainly due to exposure of film sample in ambient atmosphere after conducting the tribo-tests. Further, the location $\left(b_{2}\right)$ in Figure $8 \mathrm{a}$ contains much oxygen contamination as shown by decrease in $\mathrm{C} / \mathrm{O}$ ratio (Figure $8 \mathrm{~b}$ ). This could be related to the high surface reactivity of the deformed region. Moreover, HR-XPS showed significant increase in $\mathrm{sp}^{3} / \mathrm{sp}^{2}$ ratio to 1.88 and 1.09 (Figure $8 \mathrm{c}$ and $8 \mathrm{e}$ ) in two different locations 
indicated in optical image (Figure 8a). These values are much higher as compared to tribofilm formed in AA-RT tribo-condition. Furthermore, the $\mathrm{sp}^{3} / \mathrm{sp}^{2}$ value of 1.88 in deformed location is higher than virgin film surface and this is possibly associated to the conversion of $\mathrm{sp}^{2}$ into amorphization (a-C) and disordered $\mathrm{sp}^{3}(\mathrm{t}-\mathrm{aC})$ phase in high vacuum condition. This evidence is supported by phonon behavior of these phases analyzed by Raman spectroscopy (Figure 5).The above mentioned phase transformation is realistic at high activation energy which is contributed by the high frictional energy in HV-RT tribo-condition. The photoelectron shift of O1s peaks is quite similar and comparable to the tribofilm formed in AA-RT tribo-condition, indicating surface contamination during exposure to ambient atmosphere. However, changes in intensity and photoelectron peak shift of $\mathrm{C}=\mathrm{O}, \mathrm{C}-\mathrm{O}$ and $\mathrm{C}-\mathrm{OH}$ groups are related to oxidation behavior of the carbon.

In survey spectra, $\mathrm{C} / \mathrm{O}$ ratio is much higher 2.46 and 2.42 at two different locations of the ball scar formed in HV-HT (Figure 9b) as compared to other two tribo-conditions. These are located as $\left(a_{1}\right)$ and $\left(a_{2}\right)$ in Figure 9a, respectively. Furthermore, this ratio is comparable to film surface exposed to high temperature (Figure S9a), signifying resistance to adsorption of oxygen contamination in HV-HT tribo-condition. The residual oxygen contamination thermally desorbs mainly in the high temperature and high vacuum condition due to the weakening of cohesive barrier. 

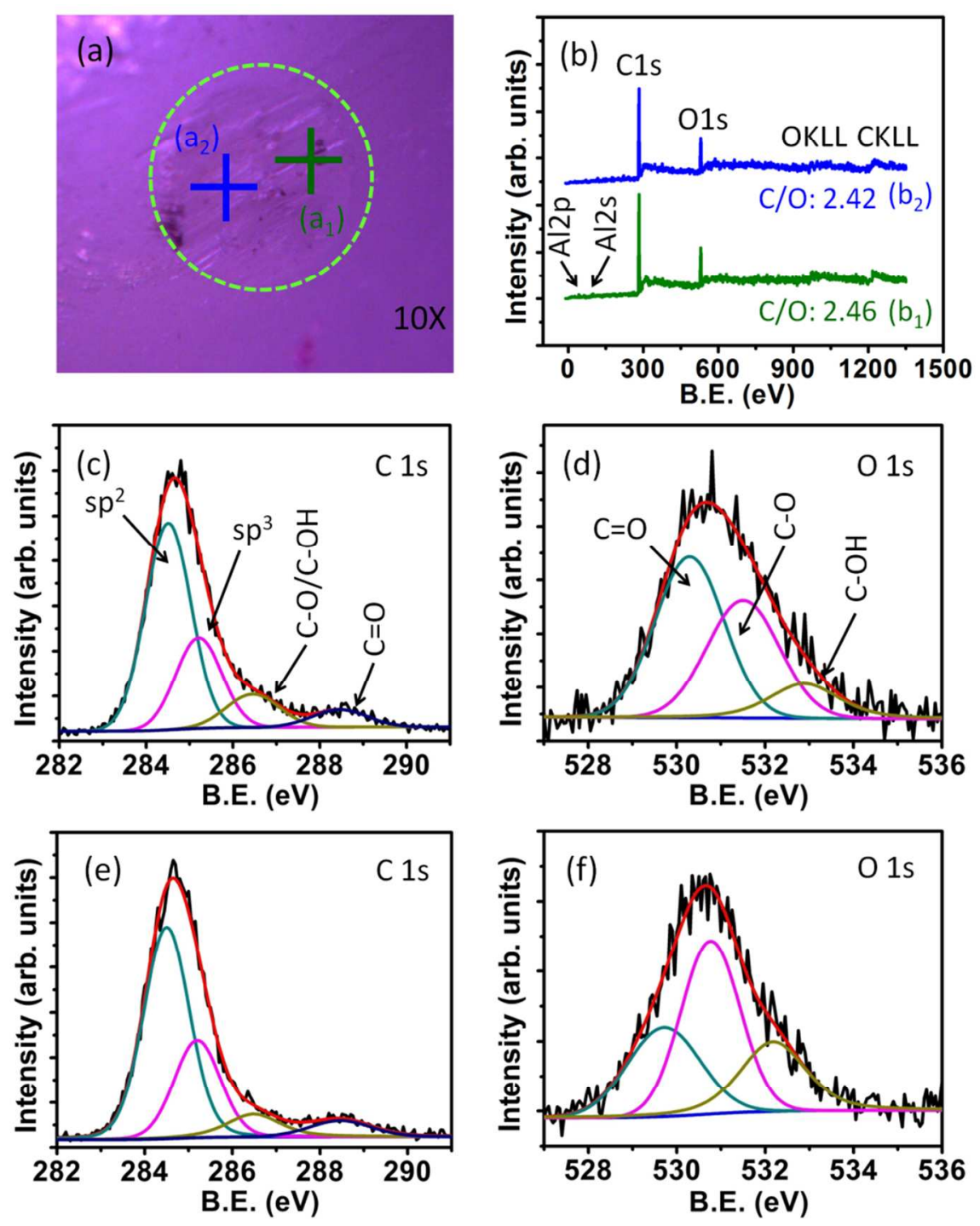

Figure 9. (a) Optical image of ball scar (HV-HT tribo-condition) locations: $\left(a_{1}\right)$ and $\left(a_{2}\right)$ and corresponding survey XPS spectra of $\left(b_{1}\right)$ and $\left(b_{2}\right)$, respectively; HR-XPS of C1s and Ols of $(c$ and $d)$ at location $\left(a_{1}\right)$ and ( $e$ and f) at locations $\left(a_{2}\right)$, respectively.

Interestingly, $\mathrm{sp}^{3} / \mathrm{sp}^{2}$ ratio of tribofilm is reduced to 0.46 and 0.42 at two different locations of ball scar (Figure 9c and 9e) as indicated in the optical image (Figure 9a). These values are much lower than virgin film surface (Figure 2c) and directly indicate the significant conversion of $\mathrm{sp}^{3}$ into $\mathrm{sp}^{2}$ phase. Such conversion was also evident in AA-RT tribo-condition to some extent but high temperature is energetically favorable for such a transformation. ${ }^{60}$ This was indicated by the 
decrease in $\mathrm{sp}^{3} / \mathrm{sp}^{2}$ value to 0.57 when the film was exposed to high temperature (Figure $\mathrm{S} 9 \mathrm{~b}$ ). Stress-induced conversion of $\mathrm{sp}^{3}$ into $\mathrm{sp}^{2}$ phase is dominating in AA-RT while stress and thermal energy both are governing factors for such conversion in HV-HT tribo-condition. Chemical characteristics of tribofilm in AA-RT and HV-HT are contrasting to HV-RT tribo-condition. The amorphization was dominated in HV-RT while graphitization occurred in AA-RT and HV-HT tribo-conditions. The conversion of ordered $\mathrm{sp}^{2}$ and $\mathrm{sp}^{3}$ phases after the amorphization was restricted in HV-RT tribo-condition. However, nucleation of ordered carbon phase in AA-RT and HV-HT was realistic due to the favorable activation energy. The contribution of functional groups in C1s photoelectron shift is suppressed at location $\left(\mathrm{a}_{2}\right)$ as indicated in Figure 9a and corresponding spectra is shown in Figure 9e. The chemical shift of these functional groups in O1s photoelectron is different at two different locations (Figure 9d and 9f) and these are associated to the chemical affinity of surface.

5. Tribology Mechanisms. Friction and wear values of UNCD NW films significantly differ depending upon the tribology test conditions (Figure 3). It is shown above that these values are high in HV-RT and significantly lower in HV-HT and AA-RT tribo-conditions. These contrasting behaviors could be explained by (a) passivation of carbon dangling bonds ${ }^{16,23}$ and (b) passivated graphitization mechanism at the sliding interfaces. Density functional theory calculations demonstrated that dissociation of $\mathrm{H}_{2}$ and $\mathrm{H}_{2} \mathrm{O}$ are energetically favorable for the passivation of dangling bonds in diamond, leading to reduction in surface energy. ${ }^{61}$ This fact is also demonstrated experimentally using spectroscopic technique by Konicek et al. in UNCD films at ambient atmosphere and room temperature tribological condition. ${ }^{16}$ Moreover, low friction of UNCD films at $200^{\circ} \mathrm{C}$ was obtained in ambient atmosphere and room temperature 
condition and this was explained by passivation mechanism. ${ }^{43}$ However, dissociative passivation mechanism of dangling bonds by ambient atmospheric $\mathrm{H}_{2}$ and $\mathrm{H}_{2} \mathrm{O}$ is restricted in high-vacuum tribo-condition (HV-RT). On the other hand, the HV-RT condition is governing factor for the transformation of diamond and graphitic phase into $\mathrm{t}-\mathrm{aC}$ and $\mathrm{a}-\mathrm{C}$ structure. This is mainly associated to tribo-contact stress and high frictional energy which restricts these carbon phases to nucleate into ordered chemical structure in the absence of passivating media. This evidence is clearly demonstrated by the Raman spectroscopy which showed increase in a-C and t-aC structure at the deformed ball scar (Figure 5). Moreover, XPS comprehensively showed large amount of $\mathrm{sp}^{3}$ fraction at the deformed ball contact (Figure 8). This is schematically presented in Figure $10 \mathrm{~b}$ and standard deviation of $\mathrm{sp}^{3} / \mathrm{sp}^{2}$ value is given in Figure $10 \mathrm{~d}$ which showed significantly large ratio. Moreover, Raman spectroscopy results showed termination of TPA phase from the tribolayer formed at ball scar (Figure $5 \mathrm{c}$ and $5 \mathrm{~d}$ ). 


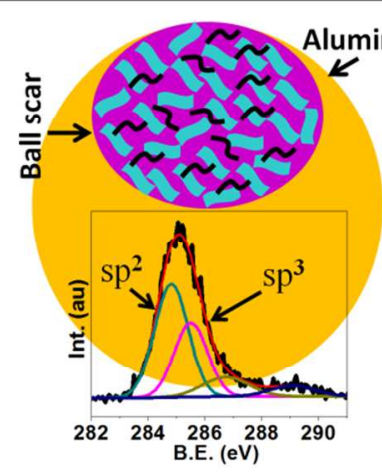

(a)

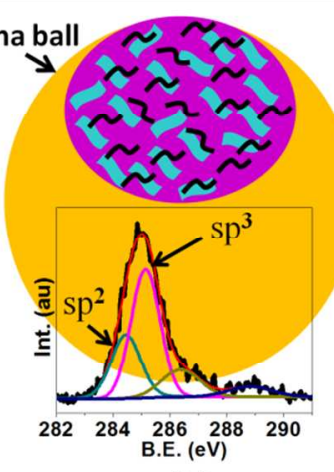

(b)

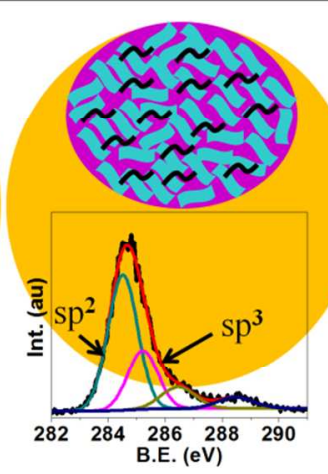

(c)

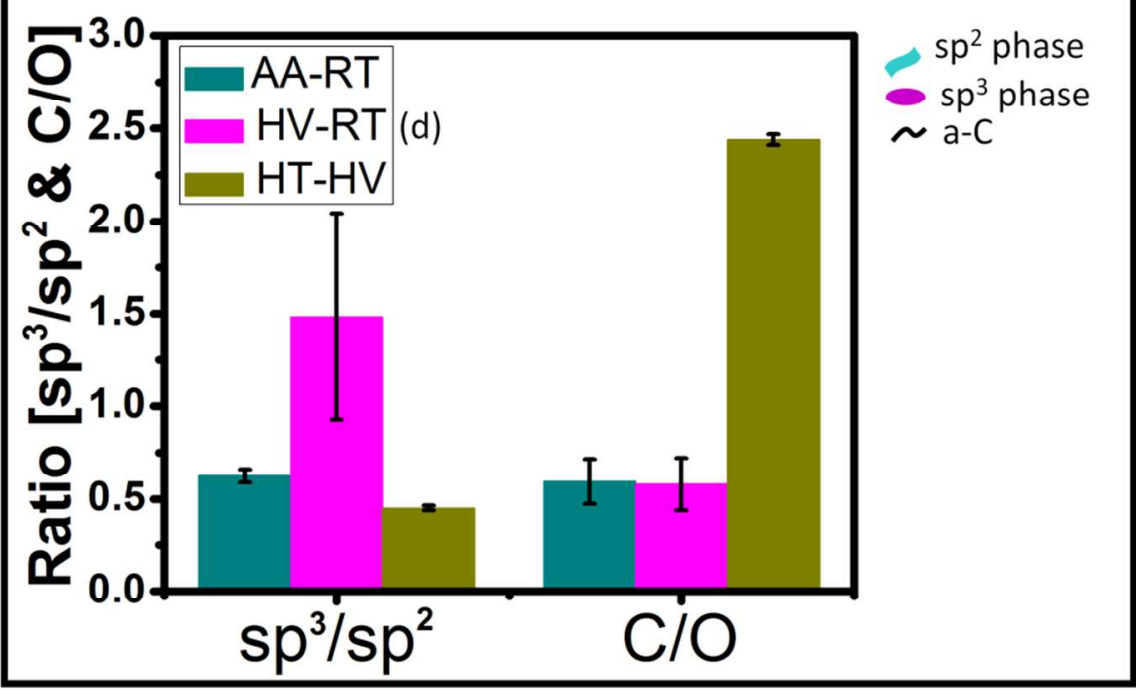

Figure 10. Schematic of carbon phase composition at tribologically deformed ball contact in (a) $A A-R T$ (b) $H V-R T$ and (c) $H V-H T$ condition with the representation of typical HR-XPS and (d) bar graph of $s p^{3} / s p^{2}$ and $C / O$ ratio with standard deviation.

The experimental facts revealed that in HV-RT tribo-condition, sliding is dominated between a-C and $\mathrm{t}-\mathrm{aC}$ structure which is known to occupy the large fraction of dangling bonds in high vacuum condition. ${ }^{62}$ The dangling bonds of carbon atoms form covalent bonds across the sliding interfaces which greatly enhanced the shear resistance. Moreover, these phases do not exhibit lamellar lattice structure and hence do not have easy tangential shearing. This causes increase in friction coefficient and wear to significantly high value which ultimately leads to partial mechanical failure of film (Figure 3a). However, passivation of dangling bonds is 
energetically favorable in AA-RT tribo-condition which results in low friction coefficient and high wear resistance. In this condition, it is believed that the dangling bonds are terminated with either $-\mathrm{OH}$ or $-\mathrm{H}$ due to the dissociation of atmospheric $\mathrm{H}_{2} \mathrm{O} \cdot{ }^{16,23,61}$ This was supported by the increase in $\mathrm{C}-\mathrm{O}$ and $\mathrm{C}=\mathrm{O}$ bonding fractions. ${ }^{16}$ To support this, our results also showed increase in oxygen and its functional groups inside the wear track in AA-RT condition (Figure 7). Moreover, passivation of dangling bonds stabilizes the chemically distorted tribolayer of a-C and $\mathrm{t}$-aC into ordered $\mathrm{sp}^{2}$ phase. Such a chemical distortion is occurred by mechanical deformation during sliding process. Here, TPA phase is preserved with its structure at contact interfaces. This evidence is clearly noticed by the XPS spectra (Figure 7) and also supported by the Raman spectroscopy (Figure 4c and 4d). In this condition, low friction and high wear resistance of UNCD NW film in AA-RT are governed by the passivation of dangling bonds and partial graphitization of tribolayer formed at the alumina ball. This is schematically presented in Figure 10a. The bar graph in Figure 10d showed statistical evidence of $\mathrm{sp}^{3}$ to $\mathrm{sp}^{2}$ transformation. This indicates that the sliding occurs between the graphitized tribolayer of ball and UNCD NW film and passivation was dominating mechanism during the interaction of sliding surfaces.

Friction coefficient and wear almost vanishes in HV-HT which is contrasting to HV-RT tribo-condition. In this case, atmospheric water vapor is restricted during tribology test and passivation mechanism of dangling bonds at contact interfaces is energetically not favorable. Therefore, in this condition, graphitization of the sliding interfaces can be considered for improving the tribological properties significantly. ${ }^{42}$ The evidence of graphitized sliding interfaces is well investigated by Raman spectroscopy (Figure 6) and XPS (Figure 9). For clear understanding, graphitized ball scar is schematically given in Figure 10c and bar graph in Figure 10d. This showed decrease in $\mathrm{sp}^{3} / \mathrm{sp}^{2}$ in HR XPS and significant increase in C/O ratio in survey 
spectra. The activation energy for graphitization is provided by film temperature during sliding process in high-temperature tribology condition. Here, frictional shear is dominated between hydrogenated graphitized interfaces that lead to ultra-low friction coefficient and wearless behavior. The hydrogen passivation of graphitized phases is intrinsically carried out by TPA phase as clearly observed by Raman spectroscopy (Figure 6). Basic mechanism which improved the tribological properties is governed by the unique lamellar lattice structure of hydrogenated $\mathrm{sp}^{2}$ phase which is environment dependent ${ }^{63}$ and shears easily with negligible tangential resistance. However, tribological properties of UNCD films at high temperature and ambient atmospheric condition were significantly degraded due to the oxidation which increases the shear resistance. $^{43}$

\section{CONCLUSIONS}

Tribological properties of UNCD NW films were investigated in AA-RT, HV-RT and HV-HT tribo-conditions. HRTEM analysis directly showed ultranano diamond grains in the film which was further supported by the Raman spectroscopy. Moreover, phase composition was investigated by XPS analysis which showed significant amount of $\mathrm{sp}^{3}$ phase of ultranano diamond grains and grain boundary of UNCD occupied by a-C and $\mathrm{sp}^{2}$ phases. Furthermore, randomly oriented nanowall morphology of the films was analyzed by high-resolution SEM. Raman spectroscopy and XPS confirmed the mechanochemical conversion of UNCD phase and tribo-environment dependent changes in chemical characteristic of tribofilm at contact interfaces. Friction coefficient was significantly high $\sim 0.17$ and wear induced film failure with wear loss of $0.006 \mathrm{~nm} /$ cycles was observed in HV-RT condition. In this case, passivation mechanism was restricted and frictional shear transformed the diamond $\mathrm{sp}^{3}$ into $\mathrm{a}-\mathrm{C}$ and $\mathrm{t}-\mathrm{aC}$ phases. However, 
passivation and graphitization were energetically favorable mechanisms in AA-RT tribocondition which reduced the friction coefficient and wear up to $\sim 0.023$ and $0.002 \mathrm{~nm} / \mathrm{cycles}$, respectively. Moreover, significant conversion of diamond $\mathrm{sp}^{3}$ into graphitized phase in the presence of internal hydrogen of film was predominant mechanism for the superlow friction coefficient $\sim 0.002$ and ultra high wear resistance of $0.0016 \mathrm{~nm} /$ cycles in HV-HT tribo-condition.

\author{
ASSOCIATED CONTENT \\ Supporting Information. Friction coefficient of UNCD NW films in AA-RT, HV-RT and HV- \\ HT tribo-condition, SEM images of the wear track and deformed ball scars, EDS analysis of the \\ wear track and deformed ball scar, Quantitative Raman data of $\mathrm{D}, \mathrm{G}$ and $\mathrm{I}(\mathrm{D}) / \mathrm{I}(\mathrm{G})$ ratio of wear \\ track in AA-RT, HV-RT and HV-HT tribo-condition, XPS spectra of UNCD NW films exposed \\ to high temperature. This material is available free of charge via Internet at http://pubs.acs.org.
}

\title{
AUTHOR INFORMATION \\ *Corresponding author \\ Email: niranjan@igcar.gov.in, \\ phystribology@gmail.com \\ Tel.: +91 4427480500 (ext. 22537) \\ Fax: +914427480081
}

NOTES

The authors declare no competing financial interest.

\section{ACKNOWLEDGMENTS}


Dr. Gomathi Natarajan (MSG/IGCAR, Kalpakkam) is acknowledged for helping in wear profile analysis with contact stylus profilometer. Kamatchi Jothiramalingam Sankaran is a Postdoctoral Fellow of the Research Foundation-Flanders (FWO). We thank the Department of Atomic Energy, India for support.

\section{REFERENCES}

(1) Hemstreet, L. A.; Fong, C. Y.; Cohen, M. L. Calculation of the Band Structure and Optical Constants of Diamond Using the Nonlocal-Pseudopotential Method. Phys. Rev. B 1970, 2, 20542063.

(2) Graebner, J. E. Measurement of Thermal Conductivity and Thermal Diffusivity of CVD Diamond. Int. J. Thermophys. 1998, 19, 511-523.

(3) Nicholson, E. D.; Field, J. E.; Partridge, P. G.; Ashfold, M. N. R. The Mechanical Properties of CVD Diamond and Diamond Coated Fibers and Wires. Mater. Res. Symp. Proc. 1996, 383, $101-113$.

(4) Miyoshi, K.; Wu, R. L. C.; Garscadden, A.; Barnes, P. N.; Jackson H. E. Friction and Wear of Plasma Deposited Diamond Films. J. Appl. Phys. 1993, 74, 4446-4454.

(5) Kumar, N.; Panda, K.; Dash, S.; Popov, C.; Reithmaier, J. P.; Panigrahi, B. K.; Tyagi, A. K.; Raj, B. Tribological Properties of Nanocrystalline Diamond Films Deposited by Hot Filament Chemical Vapor Deposition. AIP Adv. 2012, 2, 032164-032177.

(6) Lei, X.; Shen, B.; Chen, S.; Wang, L.; Sun, F. Tribological Behavior between Micro- and Nano-crystalline Diamond Films under Dry Sliding and Water Lubrication. Tribol. Int. 2014, 69, $118-127$.

(7) Takama, T.; Tsuchiya, K.; Kobayashi, K.; Sato, S. Measurement of the Structure Factors of Diamond. Acta Cryst. 1990, A46, 514-517.

(8) Gracio, J. J.; Fan, Q. H.; Madaleno, J. C. Diamond Growth by Chemical Vapour Deposition. J. Phys. D: Appl. Phys. 2010, 43, 374017-374038.

(9) Sankaran, K. J.; Kunuku, S.; Leou, K. C.; Tai, N. H.; Lin, I. N. Enhancement of the Electron Field Emission Properties of Ultrananocrystalline Diamond Films via Hydrogen Post-Treatment. ACS Appl. Mater. Interfaces 2014, 6, 14543-14551. 
(10) Sankaran, K. J.; Chen, H. C; Panda, K.; Sundaravel, B.; Lee, C. Y.; Tai, N. H.; Lin, I. N. Enhanced Electron Field Emission Properties of Conducting Ultrananocrystalline Diamond Films after $\mathrm{Cu}$ and $\mathrm{Au}$ Ion Implantation. ACS Appl. Mater. Interfaces 2014, 6, 4911-4919.

(11) Rani, R.; Kumar, N.; Kozakov, A. T.; Googlev, A. K.; Sankaran, K. J.; Das, P. K.; Dash, S.; Tyagi, A. K.; Lin, I. N. Superlubrication Properties of Ultra-nanocrystalline Diamond Film Sliding against a Zirconia Ball. RSC Adv. 2015, 5, 100663-100673.

(12) Rani, R.; Sankaran, K. J.; Panda, K.; Kumar, N.; Ganesan, K.; Chakravarty, S.; Lin, I. N. Tribofilm Formation in Ultrananocrystalline Diamond Film. Diam. Relat. Mater. 2017, 78, 1223.

(13) Sobaszek, M.; Siuzdak, K.; Ryl, J.; Sawczak, M.; Gupta, S.; Carrizosa, S. B.; Ficek, M.; Dec, B.; Darowicki, K.; Bogdanowicz, R. Diamond Phase $\left(\mathrm{sp}^{3}-\mathrm{C}\right)$ Rich Boron-Doped Carbon Nanowalls $\left(\mathrm{sp}^{2}-\mathrm{C}\right)$ : Physicochemical and Electrochemical Properties. J. Phys. Chem. C, 2017, $121,20821-20833$.

(14) Siuzdak, K.; Ficek, M.; Sobaszek, M.; Ryl, J.; Gnyba, M.; Niedziałkowski, P.; Malinowska, N.; Karczewski, J.; Bogdanowicz, R. Boron-Enhanced Growth of Micron-Scale Carbon-Based Nanowalls: A Route toward High Rates of Electrochemical Biosensing. ACS Appl. Mater. Interfaces, 2017, 9, 12982-12992.

(15) Bouchet, M. I. D. B.; Matta, C.; Vacher, B.; Magne, T. L.; Martin, J. M.; Lautz, J. V.; Ma, T.; Pastewka, L.; Otschik, J.; Gumbsch, P.; Moseler, M. Energy Filtering Transmission Electron Microscopy and Atomistic Simulations of Tribo-induced Hybridization Change of Nanocrystalline Diamond Coating. Carbon 2015, 87, 317-329.

(16) Konicek, A. R.; Grierson, D. S.; Gilbert, P. U. P. A.; Sawyer, W. G.; Sumant, A. V.; Carpick, R. W. Origin of Ultralow Friction and Wear in Ultrananocrystalline Diamond. Phys. Rev. Lett. 2008, 100, 235502-235505.

(17) Polaki, S. R.; Kumar, N.; Madapu, K.; Ganesan, K.; Krishna, N. G.; Srivastava, S. K.; Abhaya, S.; Kamruddin, M.; Dash, S.; Tyagi, A. K. Interpretation of Friction and Wear in DLC Film: Role of Surface Chemistry and Test Environment. J. Phys. D: Appl. Phys. 2016, 49, $445302-445314$.

(18) Polaki, S. R.; Kumar, N.; Ganesan, K.; Madapu, K.; Bahuguna, A.; Kamruddin, M.; Dash, S.; Tyagi, A. K. Tribological Behavior of Hydrogenated DLC Film: Chemical and Physical Transformation at Nano-scale. Wear 2015, 338-339, 105-113. 
(19) Bai, L.; Zhang, G.; Lu, Z.; Wu, Z.; Wang, Y.; Wang, L.; Yan, P. Tribological Mechanism of Hydrogenated Amorphous Carbon Film against Pairs: A Physical Description. J. Appl. Phys. 2011, 110, 033521-033528.

(20) Cui, L.; Lu, Z.; Wang, L. Probing the Low-Friction Mechanism of Diamond-Like Carbon by Varying of Sliding Velocity and Vacuum Pressure. Carbon 2014, 66, 259-266.

(21) Ma, T. B.; Wang, L. F.; Hu, Y. Z.; Li, X.; Wang, H. A Shear Localization Mechanism for Lubricity of Amorphous Carbon Materials. Sci. Rep. 2014, 4, 3662-3667.

(22) Kumar, N.; Radhika, R.; Kozakov, A. T.; Sankaran, K. J.; Dash, S.; Tyagi, A. K.; Tai, N. H.; Lin, I. N. Humidity-Dependent Friction Mechanism in an Ultrananocrystalline Diamond Film. J. Phys. D: Appl. Phys. 2013, 46, 275501-275508.

(23) Bouchet, M. I. D. B.; Zilibotti, G.; Matta, C.; Righi, M. C.; Vandenbulcke, L.; Vacher, B.; Martin, J. M. Friction of Diamond in the Presence of Water Vapor and Hydrogen Gas. Coupling Gas-Phase Lubrication and First-Principles Studies. J. Phys. Chem. C 2012, 116, 6966-6972.

(24) Qin, W.; Yue, W.; Wang, C. Understanding Integrated Effects of Humidity and Interfacial Transfer Film Formation on Tribological Behaviors of Sintered Polycrystalline Diamond. RSC Adv. 2015, 5, 53484-53496.

(25) Manelli, O.; Corni, S.; Righi, M. C. Water Adsorption on Native and Hydrogenated Diamond (001) Surfaces. J. Phys. Chem. C 2010, 114, 7045-7053.

(26) Sankaran, K. J.; Kumar, N.; Kurian, J.; Radhika, R.; Chen, H. C.; Dash, S.; Tyagi, A. K.; Lee, C. Y.; Tai, N. H.; Lin, I. N. Improvement in Tribological Properties by Modification of Grain Boundary and Microstructure of Ultrananocrystalline Diamond Films. ACS Appl. Mater. Interfaces 2013, 5, 3614-3624.

(27) Kunze, T.; Posselt, M.; Gemming, S.; Seifert, G.; Konicek, A. R.; Carpick, R. W.; Pastewka, L.; Moseler, M. Wear, Plasticity, and Rehybridization in Tetrahedral Amorphous Carbon. Tribol. Lett. 2014, 53, 119-126.

(28) Zhang, X.; Schneider, R.; Muller, E.; Mee, M.; Meier, S.; Gumbsch, P.; Gerthsen, D. Electron Microscopic Evidence for a Tribologically Induced Phase Transformation as the Origin of Wear in Diamond. J. Appl. Phys. 2014, 115, 063508-063513.

(29) Pastewka, L.; Moser, S.; Gumbsch, P.; Moseler, M. Anisotropic Mechanical Amorphization Drives Wear in Diamond. Nat. Mater. 2011, 10, 34-38.

(30) Erdemir, A.; Fenske, G. R. Tribological Performance of Diamond and Diamondlike Carbon Films at Elevated Temperatures. Tribol. T. 1996, 39:4, 787-794. 
(31) Wu, W. J.; Hon, M. H. Thermal Stability of Diamond-like Carbon Films with Added Silicon. Surf. Coat. Technol. 1999, 111, 134-140.

(32) Li, J.; Yue, W.; Qin, W.; Wang, C. Approach to Controllable Tribological Properties of Sintered Polycrystalline Diamond Compact through Annealing Treatment. Carbon, 2017, 116, 103-112.

(33) Shabani, M.; Abreu, C. S.; Gomes, J. R.; Silva, R. F.; Oliveira, F. J. Effect of Relative Humidity and Temperature on the Tribology of Multilayer Micro/nanocrystalline CVD Diamond Coatings. Dia. Relat. Mater. 2017, 73, 190-198.

(34) Krauss, A. R.; Auciello, O.; Gruen, D. M.; Jayatissa, A.; Sumant, A.; Tucek, J.; Mancini, D. C.; Moldovan, N.; Erdemir, A.; Ersoy, D.; Gardos, M. N.; Busmann, H. G.; Meyer, E. M.; Ding, M. Q. Ultrananocrystalline Diamond Thin Films for MEMS and Moving Mechanical Assembly Devices. Dia. Relat. Mater. 2001, 10, 1952-1961.

(35) Gardos, M. N. Tribological Fundamentals of Polycrystalline Diamond Films. Surf. Coat. Technol. 1999, 113, 183-200.

(36) Gardos, M. N. Surface Chemistry-Controlled Tribological Behavior of Silicon and Diamond. Tribol. Lett. 1996, 2, 173-187.

(37) Gardos, M. N.; Soriano, B. L. The Effect of Environment on the Tribological Properties of Polycrystalline Diamond Films. J. Mater. Res. 1990; 5, 2599-2609.

(38) Miyoshi, K. Considerations in Vacuum Tribology (Adhesion, Friction, Wear, and Solid Lubrication in Vacuum). Tribol. Int. 1999, 32, 605-616.

(39) Feng, Z.; Tzeng, Y.; Field, J. E. Friction of Diamond on Diamond in Ultra-High Vacuum and Low-Pressure Environments. J. Phys. D: Appl. Phys. 1992, 25, 1418-1424.

(40) Aggleton, M.; Burton, J. C.; Taborek, P. Cryogenic Vacuum Tribology of Diamond and Diamond-Like Carbon Films. J. Appl. Phys. 2009, 106, 013504-013509.

(41) Yu, X.; Ai, J.; Yang, L.; Wang, C. Exploring Tribological Behaviour of Diamond Film by Hot-Filament Chemical Vapour Deposition on Tungsten Carbide for Lunar Exploration. Vacuum 2014, 100, 41-45.

(42) Liu, Y.; Yue, W.; Qin, W.; Wang, C. Improved Vacuum Tribological Properties of Sintered Polycrystalline Diamond Compacts Treated by High Temperature Annealing. Carbon 2017, 124, 651-661.

(43) Ramadoss, R.; Kumar, N.; Sankaran, K. J.; Das, P.; Ravindran, T. R.; Dash, S.; Tyagi, A. K.; Tai, N. H.; Lin. I. N. Temperature Dependent Tribological Studies and Phase Transformation in Ultra-Nanocrystalline Diamond Films. Sci. Adv. Mater. 2014, 6(4), 1-9. 
(44) Bogdanowicz, R.; Sobaszek, M.; Ryl, J.; Gnyba, M.; Ficek, M.; Gołuński, Ł.; Bock, W. J.; Śmietana, M.; Darowicki, K. Improved Surface Coverage of an Optical Fibre with Nanocrystalline Diamond by the Application of Dip-Coating Seeding. Diam. Relat. Mater. 2015, $55,52-63$.

(45) Hirai H.; Kondo, K. I. Modified Phases of Diamond Formed under Shock Compression and Rapid Quencing. Science 1991, 253, 772-774.

(46) Kovarik, P.; Bourdon, E. B. D.; Prince, R. H. Electron-Energy-Loss Characterization of Laser-Deposited a-C, a-C:H, and Diamond Films. Phys. Rev. B 1993-II, 48, 12123-12130.

(47) Birrell, J.; Gerbi, J. E.; Auciello, O.; Gibson, J. M.; Johnson, J.; Carlisle, J. A. Interpretation of the Raman Spectra of Ultrananocrystalline Diamond. Diam. Relat. Mater. 2005, 14, 86-92.

(48) Pfeiffer, R.; Kuzmany, H.; Knoll, P.; Bokova, S.; Salk, N.; Gunther, B. Evidence for TransPolyacetylene in Nano-crystalline Diamond Films. Diam. Relat. Mater. 2003, 12, 268-271.

(49) López-R1'os, T.; Sandré, É.; Leclercq, S.; Sauvain, É. Polyacetylene in Diamond Films Evidenced by Surface Enhanced Raman Scattering. Phy. Rev. Lett. 1996, 76, 4935-4938.

(50) Ferrari, A. C.; Robertson, J. Resonant Raman Spectroscopy of Disordered, Amorphous, and Diamondlike Carbon. Phys. Rev. B. 2001, 64, 075414-075426.

(51) Vlasov, I. I.; Goovaerts, E.; Ralchenko, V. G.; Konov, V. I.; Khomich, A. V.; Kanzyuba, M. V. Vibrational Properties of Nitrogen-Doped Ultrananocrystalline Diamond Films Grown by Microwave Plasma CVD. Diam. Relat. Mater. 2007, 16, 2074-2077.

(52) Al-Riyami, S.; Ohmagari, S.; Yoshitake, T. X-ray Photoemission Spectroscopy of Nitrogen-Doped UNCD/a-C:H Films Prepared by Pulsed Laser Deposition. Diam. Relat. Mater. 2010, 19, 510-513.

(53) Shirley, D. A. High-Resolution X-Ray Photoemission Spectrum of the Valance Bands of Gold. Phys. Rev. B 1972, 5, 4709-4714.

(54) Merel, P.; Tabbal, M.; Chaker, M.; Moisa, S.; Margot, J. Direct Evaluation of the $\mathrm{sp}^{3}$ Content in Diamond-Like-Carbon Films by XPS. Appl. Surf. Sci. 1998, 136, 105-110.

(55) Ren, B.; Huang, J.; Yu, H.; Yang, W.; Wang, L.; Pan, Z.; Wang, L. Thermal Stability of Hydrogenated Diamond Films in Nitrogen Ambience Studied by Reflection Electron Energy Spectroscopy and X-ray Photoelectron Spectroscopy. Appl. Surf. Sci. 2016, 388, 565-570.

(56) Abhijit, G.; Surbhi, S.; Papakonstantinou, P.; Hamilton, J. Probing the Thermal Deoxygenation of Graphene Oxide Using High-Resolution In Situ X-ray-Based Spectroscopies. J. Phys. Chem. C 2011, 115, 17009-17019. 
(57) Ferrari, A. C.; Robertson, J. Interpretation of Raman Spectra of Disordered and Amorphous Carbon. Phys. Rev. B. 2000, 61, 14095-14107.

(58) Schwan, J.; Ulrich, S.; Batori, V.; Ehrhardt, H.; Silva, S. R. P. Raman Spectroscopy on Amorphous Carbon Films. J. Appl. Phys. 1996, 80, 440-447.

(59) Joly-Pottuz, L.; Matta, C.; Bouchet, M. I. D. B.; Vacher, B.; Martin, J. M.; Sagawa, T. Superlow Friction of $t a-\mathrm{C}$ Lubricated by Glycerol: An Electron Energy Loss Spectroscopy Study. J. Appl. Phys. 2007, 102, 064912-064920.

(60) Mangolini, F.; Rose, F.; Hilbert, J.; Carpick, R. W. Thermally Induced Evolution of Hydrogenated Amorphous Carbon. Appl. Phys. Lett. 2013, 103, 161605-161609.

(61) Qi, Y.; Konca, E.; Alpas, A. T. Atmospheric Effects on the Adhesion and Friction Between Non-Hydrogenated Diamond-Like Carbon (DLC) Coating and Aluminum - A First Principles Investigation. Surf. Sci. 2006, 600, 2955-2965.

(62) Erdemir, A.; Donnet, C. Tribology of Diamond-Like Carbon Films: Recent Progress and Future Prospects. J. Phys. D: Appl. Phys. 2006, 39, 311-327.

(63) Yen, B. K. Influence of Water Vapor and Oxygen on the Tribology of Carbon Materials With $\mathrm{sp}^{2}$ Valence Configuration. Wear 1996, 192, 208-215. 
TOC Graphic

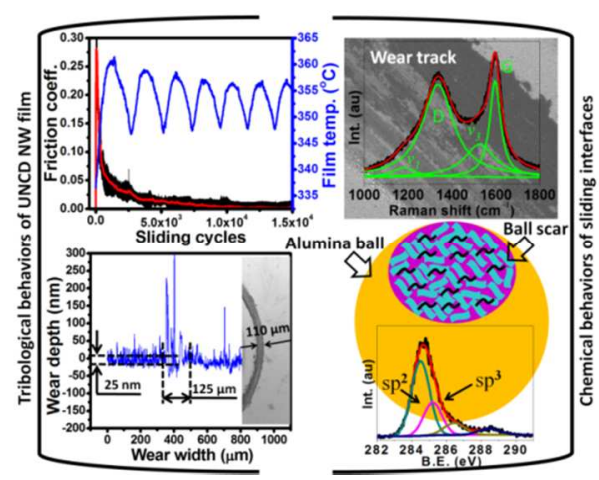

